\title{
Exploring the Nexus Between Culture, Values, Institutions, Happiness and Philanthropy: A Global Evidence
}

\author{
Maham Mushtaq \\ Research Scholar \\ Karachi University Business School, University of Karachi \\ Main University Rd, Karachi, Pakistan \\ E-mail: mahammushtaq24@gmail.com \\ Dr. Danish Ahmed Siddiqui \\ Associate Professor \\ Karachi University Business School, University of Karachi \\ Main University Rd, Karachi, Pakistan \\ E-mail: daanish79@hotmail.com
}

Received: February 1, 2020 Accepted: March 12, 2020 Published: March 17, 2020

doi:10.5296/ijsw.v7i1.16366 URL: https://doi.org/10.5296/ijsw.v7i1.16366

\begin{abstract}
The main aim of this study was to investigate the impact of culture, values, institutions, and happiness on the world's philanthropy. Culture is measured by Hofstede index (i.e. individualism-collectivism, masculinity-femininity, long and short-run orientation, uncertainty avoidance, power distance, and indulgence-restraint). The measurement of value is WVS (World Value Survey) and it consists of the emotion of happiness, active/ inactive membership of a church or religious organization, important in life; religion, confidence on charitable/ humanitarian organization and active/ inactive membership of charitable/ humanitarian organization. Institutions are measured by WGI (World Governance Indicators) and it consists of corruption, regulatory quality, accountability and voice, rule of law, political stability and government effectiveness, the sub-variables of happiness (index) are social support, freedom to take decisions and generosity and world's philanthropy is measured by
\end{abstract}


CAF (Charitable Aid Foundation) world giving index. We have gathered panel data (from the period 2010 to 2014) of CAF index, happiness index and WGI of 62 countries and cross-sectional data of CAF index, Hofstede index, WGI, happiness index and WVS of 24 countries. The result (of panel data) shows that there is a significant relation of WGI, social support and freedom of choice with CAF index whereas there is an insignificant connection between generosity and CAF index. The findings (of cross-sectional data of all factors combined) shows that there is a relation of the Hofstede index and happiness index with the CAF index while there is no linkage of WGI and WVS with the CAF index. The study suggests that charitable organizations should personify their value in order to build trust among the public. Countries should improve their governance because this will lead to equality and by doing this countries will also manage their resources efficiently and effectively.

Keywords: Culture, Values, Institutions, Happiness, Philanthropy, Cross Country

\section{Introduction}

\subsection{Background}

Over the past decades, the part that philanthropy played in strengthening civilization and addressing challenges that were faced by a human had received great attention. One problem that affects philanthropy of the world was that at the state level a complex group of socio-cultural, economic, administrative and political factors collectively form the environment for charity. This growing environment generates a problem in developing a sufficient construct in order to evaluate the enabling situations domestically as well as internationally (Garcia et al., 2017).

Philanthropic activities were revealed by monetary contributions. This kind of activity was manifested with aid provided in the shape of time, money and other sorts of resources to philanthropy. A charitable organization is basically a religious, non-profit and non-political firm. The primary responsibility of the charitable organization is to directly help the needy people, particularly when contributors and needy often contact with each other, else the contributor had know-how about where needy people lived. Now charitable organizations had become one of the most important medium for a person's monetary donation. Charitable organizations are perhaps largely recognized firms inside the not for profit division (Hassan et al., 2018).

Economic components played a great role in shaping cross-countries' disparity in donations. Charitable giving directly relates to the overall power of a nations' economy however the path of the relation is ambiguous. The economy's progress supports the enlargement of the lower class (capable enough to engage themselves in public activities). Economic expansion emphasizes on occupational specialty and societal position difference as it encourages the expansion of charitable groups. When people participate more and more in voluntary work, thus they might give money to charitable organizations. Because of economic development, wealthier people might donate more money to the charitable organization as they have more cash to donate (Einolf, 2017). 
According to cultural theories, due to differences in culture, the giving behavior also varies from country to country. One culture's values, language, ethnicity can be different from the other however the main cultural disparity is religion when it comes to donation. Charitable giving; historically embedded in ones' religious instruction i.e. to aid humanity and these sorts of aiding movement were arranged by religious practice. Charity gets affected by religious diversity and religionism and people who are very much close to their religion gave a lot of donations. Hence it can be said that countries with greater religious people rate tend to donate more money (Einolf, 2017).

Political freedom and democracy directly relate with donation since the government of political freedom countries puts few constraints on not for profit sector. Less constraint leads to powerful non-financial firms that solicit donations with lower transaction costs and lesser restrictions were put by government regulatory bodies. Likewise, the absence of manipulation and government effectiveness, society, and charitable organization were optimistically related to each other. If the government of the country is effective as well as free from corruption then it would not be difficult for not for profit organizations to accomplish lawful status and can also ask for aid excluding transaction cost (Einolf, 2017).

\subsection{Problem Statement}

Philanthropy significantly affects the nation or society. Recent laws and policies that structure or construct philanthropy basically favor wealthy people above needy people. Public policies in many countries grant great honor to donors.

Philanthropy faces challenges like limited participation by individuals in philanthropy, inadequate infrastructure and society's capacity, legitimate and financial constraints on civil society and philanthropy and values and cultural approaches that do not wholly encourage and accept the role played by philanthropy and civil society.

In many countries, several tax and legitimate obstacles restrict an individual's ability to participate fully in philanthropic activities. Some legal impediments directly stop the operation and formation of institutions of philanthropy. Other barriers involved in philanthropy; limitations on the formation of capital and donation building, tax duties on income generated through investments, law enforcement on personal financial benefit and taxes on gifts from the charity. Legal policies of civil society also affect the growth of philanthropy; consist of easy registration process of charitable organizations and sector and institutional transparency and accountability.

In a country or society, philanthropic activities can grow or flourish if society plays a vibrant and strong role for civilians of the society, admire and respect the institution of sectors and have a belief in the necessity of private performer's support. An attitude of the general public towards society is another barrier to philanthropy. In many countries, there is inadequate acceptance or approval of an intensifying role regarding civil society and lack of confidence and trust in charitable firms. Many countries have a lack of knowledge, information, understanding, and transparency regarding philanthropic activities.

The philanthropic sector lacks professional standards and the institution's capacity. Many 
countries consist of nonprofit organizations that are lacking from resources, constituency, and skills. And also lack of specialized training in divisions like fundraising, management, communication, accounting, and financial systems.

\subsection{Gap Analysis}

Luria et al, (2015) studied the relation between prosocial behaviors and national culture. The results disclosed that power distance, long-term orientation, and uncertainty of avoidance negatively correlates with prosocial behaviors whereas individualism-collectivism was optimistically correlated with prosocial behaviors and masculinity did not contribute towards prosocial behavior.

Pholphirul, (2015) studied the linkage between philanthropy and happiness level. In this study, religious and non-religious giving were the independent variables whereas happiness was the dependent variable. The outcomes revealed that religious and non-religious giving significantly influenced happiness.

Einolf, (2017) studied the influence of various factors on donation. The results of the study revealed that political and economic factors strongly support donations whereas religious and cultural factors partially support donations. Thus it can be said that the pattern of donation gets more affected by economic and political factors as compared to religion and cultural factors.

Borgonovi, (2008) examined the linkage among volunteering and well-being (i.e. value).The estimates showed that people who are involved in volunteering are more happy and have better health than people who are not involved. The results of the study revealed that religious volunteering positively and significantly affects happiness but not health. A volunteer will be happy whether the status is low or high. Volunteering affects happiness by increasing empathic emotions etc.

Many types of research had been conducted on culture, value, institutions, happiness, and philanthropy separately globally. However, past studies focused on the effect of a single element on philanthropy. All these factors affect philanthropy at the same time, therefore, they need to be included in a single model. Hence, no comparative study has ever been conducted on (all of the five factors together) culture, value, institutions, happiness, and philanthropy.

\subsection{Objectives of the Study}

The aim of this paper was to found the impact of culture, value, institution, and happiness on the world's philanthropy. Culture, value, institution, and happiness were taken as the independent variables while the world's philanthropy was the dependent variable. Culture was measured by Hofstede index (Dulababu, 2017; Stojcic et al., 2016; Irfan, 2016; Ye et al., 2015; Luria et al., 2015; Smith, 2015), value was measured by WVS (Matei \& Abrudan, 2018; Dimitrova et al., 2016; Ye et al., 2015; Smith, 2015), the measurement of institution was WGI (Helliwell et al., 2018; Awan et al., 2018; Einolf, 2017; Bayar, 2016; Asuquo, 2015), happiness was indicated by happiness index (Helliwell et al., 2018; Dulababu, 2017) and 
philanthropy was measured by CAF index (Einolf, 2017; Stojcic et al., 2016; Pholphirul, 2015; Luria et al., 2015; Smith, 2015).

Our study explores the nexus between the independent variable (like culture, values, institutions, and happiness) and the dependent variable (i.e. philanthropy) globally. In this study, we have gathered cross-sectional (of 24 countries) and panel data (of 62 countries) from secondary sources like Hofstede index, World Value Survey, World Governance Indicators, Happiness Index and CAF Index. Panel data was acquired from the period 2010 to 2014 (i.e. five years). We analyzed data with the help of correlation, regression and descriptive statistics.

\subsection{Research Question}

The research questions for the study are:

- What is the impact of power distance on CAF (Charitable Aid Foundation) index?

- What is the impact of individualism-collectivism on CAF index?

- What is the impact of uncertainty avoidance on CAF index?

- What is the impact of masculinity-femininity on CAF index?

- What is the impact of indulgence-restraint on CAF index?

- What is the impact of long-short term orientation on CAF index?

- What is the impact of important in life; religion on CAF index?

- What is the impact of active/ inactive membership of church or religious organization on CAF index?

- What is the impact of active/ inactive membership of charitable/ humanitarian organization on CAF index?

- What is the impact of confidence on charitable/ humanitarian organization on CAF index?

- What is the impact of feeling of happiness on CAF index?

- What is the impact of world governance indicators on CAF index?

- What is the impact of social support on CAF index?

- What is the impact of freedom to make life choices on CAF index?

- What is the impact of generosity on CAF index?

\subsection{Significance}

This research would help in decision making related to where they should give their charity. By doing this research countries would have more awareness and will make more flexible laws for philanthropy, the regulatory framework of philanthropic activities will be improved, 
tax policies and institution's transparency and accountability will also be improved. And would aid policymakers by providing them the edge needed in considering the governmental, cultural and economic issues in the implementation, design, and formulation of public policy in a region.

This problem or research is significant because it will provide better understanding and information globally to people who want to involve themselves in philanthropic activities since philanthropy is essential because it diminishes inequality among developing countries in many ways. Like global foundations especially in Europe and USA distribute donations, gifts, grants, etc. to developing countries and also developing countries emerges and expands indigenous philanthropy. These various procedures of philanthropy leverage financial capital just to address various kinds of inequality. And globally people should be aware of each of these variable's impact else they will take wrong decisions and can get themselves into trouble and furthermore through awareness people's attitude, practices and values towards philanthropy would also change.

\section{Literature Review}

In this section, we will do the review of previous research papers that are related to the impact of culture, value, institutions, and happiness on the world's philanthropy.

Helliwell et al. (2018) examined the connection between the nation's well-being and governance. Governance was the independent variable measured by democratic quality (average of voice accountability and political stability), delivery quality (average of control corruption, government effectiveness, regularity quality and rule of law), index of civil liberties, corruption perception, political rights, and economy's freedom and confidence in national government. Nation's well-being was the dependent variable and its measurements were social support, freedom of life choices, generosity, GDP per capita and expectation of healthy life. As a sample 57 countries were selected and data were acquired from secondary sources (like Gallup world's poll, world governance indicators, an indicator of world development, etc.) from the year 2005 to 2012 and this research took place in 2018 . Regression analysis was used and the previous findings showed that delivery quality controls democratic quality in order to support a better standard of living and also democratic quality optimistically affects nations with good delivery quality. The new findings indicated that people are pleased with their life because of good governance and quality of life had also improved due to great alterations in governance quality (i.e. delivery and democratic quality).

Hassan et al. (2018) explored the linkage between perceived ability, perceived integrity, trust disposition, perceived benevolence, and the charitable organization. The charitable organization was the dependent variable. While perceived ability, perceived integrity, trust disposition, and perceived benevolence were the independent variables. The data for the research was collected through primary sources like questionnaires and surveys from 258 respondents. This study took place in Malaysia in the year 2018. Smart PLS was used for analysis. The outcomes of the study showed that there was a direct relation among perceived ability, perceived integrity, perceived benevolence, and the charitable organization. Whereas a small linkage was found between trust disposition and the charitable organization. 
Awan et al. (2018) determined the linkage between governance and economic growth. Governance was the independent variable measured by political stability, corruption, education index, and government effectiveness and economic growth was the dependent variable indicated by GDP per capita. The data was extracted from WGI, HDI (Human Development Index) and WDI (World Development Index) from the year 1996 to 2014 and out of 8 SAARC countries only 5 member's data was collected. This research was conducted in 2018. Regression was applied with the help of the Fixed Effect Model and for model specification, Hausman and fixed effect test (redundant) was used. The outcomes of the study showed that political stability, education index, corruption, and government effectiveness significantly influenced economic growth.

Matei and Abrudan, (2018) investigated that national culture (or people's perception) varies from nation to nation. The data was collected from WVS and EVS (European Value Survey), from 1990 to 2014. As a sample 13 countries were selected to conduct the research. This research was quantitative. To measure people's perception the researcher measured that among work, friends, leisure time, family, religion, and politics what is most important in a person's life. The findings of this paper showed that some country's culture was highly stable as compare to others. Whereas those cultures that were changing changes very fast. Therefore it can be said that social, economic factors or natural circumstances affect people's perception.

Einolf, (2017) studied the influence of cross countries on donation. The independent variables that were used in this research; GDP per capita and government expenditure (both of them are part of economic theories), civil liberties, communism, corruption, government effectiveness and country's age (all of them are part of political theories), religious diversity, linguistic diversity, ethnic diversity (all of them are part of cultural theories), religiosity, percentage of Muslims, Jewish, Buddhist and Hindu and Percentage of Protestant and Catholic (all of them are part of religious theories) whereas the dependent variable was Donation. Correlation, regression and descriptive statistics were used in this study. A sample of 114 countries was chosen to conduct the research out of which 93 countries were nonwestern while 21 countries were western. The data for the research was acquired from secondary sources like GWP (Gallup World Poll). The results of the study revealed that political and economic theories strongly support donations whereas religious and cultural theories partially support donations. Thus it can be said that the pattern of donation gets more affected by economic and political factors as compared to religion and cultural factors.

Dulababu, (2017) examined the linkage between continents, culture, and happiness. This paper showed that happiness varies from continent to continent and from culture to culture. Happiness was the dependent variable while different cultures and continents were the independent variables. The proxies of happiness were GDP per capita, generosity, social support, the expectation of a healthy life, trust and freedom of life. While the proxies of culture were individualism-collectivism, uncertainty avoidance, power distance, short and long-run orientation, and masculinity-femininity. Different continents include Africa, Europe, Australia, North America, Asia, South America and Global (overall). The data for this paper (took place in 2017) was extracted from secondary sources like Hofstede index, world 
happiness report, etc. from the year 2010 to 2016. T-test, z-test and ANOVA single factor was applied to test and analyze the hypotheses. The results revealed that individualism-collectivism, uncertainty avoidance, and power distance significantly influenced happiness score, on the other hand, short and long-run orientation and masculinity-femininity had an insignificant relation with happiness score and the mean of happiness score varies from continent to continent but at the global level it does not fluctuate.

Çarkoğlu et al. (2017) explored the factors contributing towards philanthropy. Philanthropy was the dependent variable whereas gender (male/ female), institutional trust, economic circumstances, civic activism, income, education, marital status, age, resident, religiosity, etc. were the independent variables. The data was collected through primary sources such as interviews and a sample (random) of 2,495 citizens (Turkish) were taken. This research was held in 2015. The outcomes of this paper showed that male, institutional trust, economic circumstances, civic activism, income, education, age, resident, religiosity all of them significantly influenced philanthropy. But no relation was found between marital status and philanthropy.

Bayar, (2016) examined the impact of governance on the growth of the economy. In this paper governance was an independent variable whose proxies were regulatory quality, corruption, political stability, accountability and voice, government effectiveness and rules and regulations of law whereas economic growth was the dependent variable, measured by GDP per capita (real). The data for the paper was gathered from WGI (World Governance Indicators) and World bank (from the period 2002-2013). In this paper descriptive statistics, regression and correlation matrix were used. The outcomes indicated that there was no multicollinearity among WGI and all independent variables (except regulatory) had a significant linkage with the dependent variable. The paper recommended that developed and underdeveloped nations should improve public administration.

Dimitrova et al. (2016) determined the association between culture, retail structure and value. The panel data was acquired from WVS, WDI, planet retail, etc. of 67 countries (due to unavailability of data) from 1999-2012. Retail size and intensity were the sub variable of a dependent variable (i.e. retail structure) while self or survival expression and secular or traditional-rational were the measurements of the independent variable (i.e. culture and value). The findings of the study indicated that there is a connection between culture, value and retail structure.

Stojcic et al. (2016) determined the connection between uncertainty avoidance and charity. In this study, uncertainty avoidance was the independent variable whereas charity was the dependent variable measured by CAF index (includes helping someone, volunteering and donating) and control variables were also used such as GNI (Gross National Income per Capita), Gini Coefficient power distance and individualism or collectivism. 79 countries were chosen as a sample and data were extracted from world poll of Gallup, report of human development, etc. and correlation matrix was used in this research. The findings showed a negative correlation between uncertainty avoidance and charity.

Irfan, (2016) examined the relationship between culture and organizational performance. In 
this paper culture was an independent variable and its sub-variables were individualism-collectivism, power distance, uncertainty avoidance, and masculinity-femininity. The organizational performance was the dependent variable. This study was conducted in Srilanka. The data for the research (i.e. qualitative) was extracted from secondary sources like newspapers, articles, books, journals, etc. In Srilanka, masculinity and uncertainty avoidance were low whereas power distance and collectivism were high and moderate respectively. The outcomes of the study revealed that there was a significant relation between cultural dimensions and organizational performance. The positive culture of the organization, good mission, and vision, sustain and equity democratic system, etc. can improve a firm's performance.

Ye et al. (2015) examined the relation between culture and happiness and a sample of 48 countries was taken. The culture was an independent variable whose proxies were Institutional collectivism, power distance, assertiveness, human orientation, gender egalitarianism, performance orientation, uncertainty avoidance, future orientation, and in-group collectivism while happiness was the dependent variable whose sub variable was SWB (Subjective Well-Being). Control variables were also used in this research such as population density, education, human rights, GDP in dollars, GDP's growth rate, GDP per capita and language dummies. The data for the research was acquired from secondary sources like WVS, Hofstede index, global cultural indices, etc. from the period 1990 to 2006. Descriptive statistics, correlation matrix, and regression were applied to determine the relation between independent and dependent variables. In this paper, two types of regression were run such as OLS (Ordinary Least Square) and GMM (Generalized Method of Moments). The findings of the study showed that all of the independent and control variables significantly influence the SWB but gender egalitarianism and power distance played a major role in examining SWB.

Pholphirul, (2015) studied the linkage between philanthropy and happiness level. In this study, religious and non-religious giving were the independent variables whereas happiness was the dependent variable. The sub variable of happiness was SWB (Subjective Well Being) and religious giving was measured by food or non-food contribution to Buddhist monks and non-religious giving was measured by volunteer work and donation in the form of money or goods. While marital status, gender, educational attainment, age, occupation, and religion are the control variables. The data for the study was gathered from secondary sources like a survey that was conducted on cultural and society's condition in the year 2011 in Thailand. The ordinary least square ordered logit and ordered probit model were used. The outcomes revealed that religious and non-religious giving significantly influenced happiness.

Luria et al. (2015) studied the relation between prosocial behaviors and national culture. National culture was the independent variable whose sub-variables were individualism-collectivism, masculinity, long-run orientation, the uncertainty of avoidance and power distance and prosocial behaviors was the dependent variable. There were two control variables in the research such as religious heterogeneity and HDI (Human Development Index). 66 countries were chosen as a sample and the data for this paper was taken from secondary sources like the Hofstede index and Gallup survey. This study was 
conducted in 2015. The statistical tools that were used in this research; correlation, regression, and descriptive statistics. The results disclosed that power distance, long-term orientation, and uncertainty of avoidance negatively correlates with prosocial behaviors whereas individualism-collectivism was optimistically correlated with prosocial behaviors and masculinity did not contribute towards prosocial behavior.

Asuquo, (2015) investigated the relation between institution and economic performance in SSA (Sub Saharan African Region). The data was collected from the period of 2002 to 2013 (i.e.12 years) from WGI. The sub-variables of institutions were government effectiveness, corruption, political stability, regulatory quality, accountability and law's rule. The SGMM (System Generalized Method of Moment) tool was used. The results showed that economic performance had no relation with regulatory quality, political stability, rule, and accountability while corruption and government effectiveness had a relation with economic performance.

Smith, (2015) investigated the impact of cross-culture, wealth, uncertainty avoidance and in-group favoritism on giving behavior. Giving behavior was the dependent variable and its proxy was CAF index (consist of helping strangers, donating and volunteering) whereas wealth, income equality, trust, embeddedness, in-group favoritism, religious norms, and uncertainty avoidance were the independent variables. Data was acquired from secondary sources like WVS, CAF index, Hofstede index, etc. of only 135 countries. The results of the study revealed that wealth had a strong correlation with the donation as compare to helping strangers and volunteering. On the other hand higher uncertainty avoidance, income equality, trust, embeddedness, and in-group favoritism will cause lower donation, helping strangers and volunteering and higher religious norms will cause a higher CAF index.

Borgonovi, (2008) examined the association between value and philanthropy. The measurement of value is the emotion of happiness and the sub variable of philanthropy is volunteering. The evaluations showed that people who are involved in volunteering are more happy and has a better health. This investigation concentrated on voluntary work for religious organizations and groups and the statistical tool of regression was used. The results of the study revealed that religious volunteering positively and significantly affects happiness but not health. The volunteer will be happy whether the status is low or high. Volunteering affects happiness by increasing empathic emotions etc.

\section{Theoretical Framework}

\subsection{Culture}

The culture was originated from the word 'colere' which indicates cultivation, earth, nurture, and growth. Culture increases deposited knowledge, meanings, society, spatial relations, hierarchies, experience, etc. Hofstede reconciles historical, biological, philosophical explanations, etc. that he presented for cultural dimensions of work associated with ethics, values, morals, etc. it can be said that culture had sneaked in all areas of our society, religious and ethnic groups, etc. (Irfan, 2016). Culture can be defined as the grouped programming of the mentality that differentiates one person from the other. From one generation to another 
culture does not change (Ye et al., 2015).

Culture is depicted as the attitude, beliefs and moral values of people. Culture is a combined phenomenon as it is shared with the public or people living in society (Irfan, 2016). Culture not only affects social norms but it also influences economic performance. Culture is the combined programming of the brain that differentiates one type of person from the other (Ye et al., 2015). Due to Differences in culture individual's attitudes, emotions, opinions, etc. also vary. People belonging to different cultures have different values, perceptions, lifestyles, work etiquettes, etc. (Rinuastuti et al., 2014).

Hofstede's cultural model was established by IBM employees in order to aid cross-national (or cultural) management. In 1954 Levinson and Inkeles established a system to evaluate the globe's culture on the basis of their views regarding the self-concept, link with the authority, style of conflict resolution. In 1961 Strodtbeck and Kluckhorn introduced a theory about the culture which contains time sense, the relation between man and nature, human nature and social relations. Other researchers like Naroll in 1970 and Driver in 1983 did some sort of amendment to these theories (Whalen, 2016).

In 1980 Geert Hofstede compared to culture on the basis of representative survey respondents. Hofstede first compared the data of 160 questionnaires filled by IBM employees (almost 88000 employees). The data was gathered in 2 waves; in 1967 and 1972. Hofstede structured responses according to respondent's citizenship and evaluate them with the help of factor analysis (exploratory). Hofstede said that his questionnaire produce answers in four groups and these groups showed significant association among countries. These four groups are named; masculinity-femininity, power distance, uncertainty avoidance, and individualism-collectivism. One of the most interesting features of Hofstede's dimension was that they establish dimensions inductively not deductively. The anthropological theory does not show an entire view of cultural differences. This shows that if other differences arise then they will be added to Hofstede's framework. The previous cultural framework was Euro-centric and does not represent the values of East Asia efficiently (Whalen, 2016).

There is a difference between culture and values. Culture is a collective phenomenon as it is shared with the community or individuals existing in society (Irfan, 2016). Culture represents shared meaning, like ideas embodied in people's minds, sanctioned in individual's practices. Value is basically a form of mental demonstration that is mostly linked with the behaviors of people. Individuals rationalize or explain their behavior, activities or actions through values. Culture is something that people inherit from their networks, traditions, tribes with which people of the community are connected, shared in numerous manners and to changing units (Morris, 2014).

There are six dimensions of culture (Masculinity-Femininity, Long-Run Orientation Short-Run Orientation, Uncertainty of Avoidance, Individualism-Collectivism, Indulgence-Restraint and Power Distance) which were introduced by Greet Hofstede (Andrijauskienė \& Dumčiuvienė, 2017).

Power Distance shows that people with less power believe that authority is distributed 
unevenly among all the members (Andrijauskienė \& Dumčiuvienė, 2017). Power Distance, measures members of the culture believe that there is an unequal distribution of power. PDI is high when there are complex hierarchies, organizations are centralized and gaps in respect, authority, and compensation. PDI is low when firms are flatter, employees and supervisors are treated equally (Andrijauskienė \& Dumčiuvienè, 2017).

Low power distance nations belief that rights and treatment is unjustified (i.e unequal distribution) while high power distance nations belief that rights and treatment is justified (i.e. equal distribution has been done among individuals means individuals believe that people who are given top positions is justified and is done for the betterment of society. Asian, Arab and Latin countries have high power distance while low power distance is found among European (Western) countries (Luria et al., 2015).

Nations with high power distance will not work for transformation and elitist charitable giving was on a huge scale since initiatives taken by subordinates are discouraged therefore little incentives to be a volunteer. High power distance countries have mostly unsuccessful empowerment interventions. Low social status people have no expectation regarding changes in the social order and do not show interest in doing anything about the change (Luria et al., 2015).

Through volunteering, individuals get relief from own problems and permit them to ease emotion of guilt regarding societal inequality and thus this is restricted to wealthy minority and showed low charitable giving behavior where power distance is high. People belonging from various status cluster do not communicate with others. Giving behavior is not supported socially. When there is high power distance then CSR (Corporate Social Responsibility) of a nation is linked with low environmental and social performance. Nations with dominant cultures bear high power distance and thus involves more in nonprofit activities (Luria et al, 2015).

In power distance, resources are distributed unequally among people. Due to this externality arises and Power distance has a negative linkage with mental health. Greater power distance causes inequalities in areas such as wealth, civil rights, prestige, and social status. Therefore there is a significant pessimistic association between happiness and power distance (Ye et al., 2015).

Masculinity-Femininity indicates that some people want heroism, material rewards, assertiveness and achievement and some look for social care, modesty, etc (Andrijauskiené and Dumčiuvienè, 2017). Masculinity-Femininity, shows society's members favor heroism, achievement or modesty. MAS is high when accomplishments and money are very important and a person has a strong ego issue. MAS is low when relationships are very much important for a person and an individual wants to live a quality life (Andrijauskienė \& Dumčiuvienè, 2017).

Masculinity focuses on work, competition, success, and performance instead of leisure. Whereas femininity shows that individuals enthusiastically participate in social activities and our suppositions are based on literature regarding gender parts in which professions like 
service-based are recognized as feminine. As compared to men women are more involved in volunteering and recognized women as more inclined and oblige towards care. So when there is masculinity in the society then there would be a low level of donating, helping strangers and volunteering. Therefore there is a linkage between giving behavior and masculinity-femininity (Luria et al., 2015).

Masculinity and femininity have a connection with happiness. Women have a greater average score of happiness as compare to men because men have a lot of stress on the job and are not much satisfied at their workplace while women have to play a lot of social roles that leads to greater self-assessed health like small rate of illness etc. (Ye et al., 2015).

Uncertainty Avoidance can be defined as some people who do not feel comfortable with ambiguity and improbability (Andrijauskienė \& Dumčiuvienè, 2017). Uncertainty Avoidance indicates society's forbearance for unclarity. UAI is high when behavior is rigid and conservative, people show their emotions and societal conventions are involved. When UAI is low when a person is opened to innovation and inclined towards decision making and learning (Andrijauskienė \& Dumčiuvienè, 2017).

Uncertainty avoidance concerns forbearance for ambiguity and uncertainty and specifies the degree to which people of the society feel comfortable or uncomfortable in unorganized circumstances. Such a kind of society reduces unusual and unknown scenarios that should provide guidance through planning and should implement regulations, rules, and laws. Societies with low uncertainty avoidance accept other's views, rules are flexible and few and various religious and philosophical beliefs coincide. In societies with high uncertainty avoidance, there is a probability that the government will establish a system that shows care towards needy people in order to reduce uncertainty arises from an organization's and individual's prosocial actions. Thus individuals who put a lot of their time in charity work might raise uncertainty. Therefore a positive relationship was seen between charitable giving and uncertainty avoidance (Luria et al., 2015).

Uncertainty avoidance has a negative significant linkage with happiness. Nervousness and stress do not occur when uncertainty avoidance is high but fewer future occasions do occur that are unpredictable (Ye et al., 2015).

Long-Run Orientation-Short-Run Orientation specifies that some people prefer long-run orientation towards foreseeable, persistence and caution while some prefer short-run societal duties (Andrijauskienė \& Dumčiuvienè, 2017). Long-run Orientation-Short-run orientation shows society's focus on the past, future, and present. Long orientation includes modesty, the emphasis is made on obligations and virtues and individuals want to know how and what rather than why. In short, people focus on why, people emphasis on rights and values and strong beliefs (Andrijauskienė \& Dumčiuvienè, 2017).

Short-run orientation includes people's focus on values and beliefs (Andrijauskienè \& Dumčiuvienè, 2017). Long-run orientation includes an individual's involvement in future intended behavior. Like investing or planning. Some countries contain five years of plans that are considered normative while other countries have little long-run aims and do less 
investment in making plans. Long and short-term orientation affects donation, volunteering and helping strangers. In long people more willingly help others (Luria et al., 2015).

Indulgence-Restraint shows that some people strictly follow their social norms and some fulfill their desires and basic necessity (Andrijauskienè \& Dumčiuvienè, 2017). Indulgence-Restraint indicates society's control over their desires and wants. Indulgence is high when an optimistic approach is used and focused should be made on personal happiness. Restraint is low when a pessimistic approach is used and behavior is rigid and controllable (Andrijauskienė \& Dumčiuvienè, 2017).

Indulgence includes emotional expression, happiness, and freedom. In indulgence, the basic necessities of human beings are satisfied more. Indulgent society encourages people to enjoy life and express feelings or emotions. People are more happy in indulgent society as compare torestraint because indulgence put lesser restrictions on people. Previous studies showed the significance of optimistic feelings in encouraging nonprofit activities because positive feelings or emotions have a linkage with the needs of people (Guo et al., 2018).

Individualism-Collectivism indicates that people of the community are joined into clusters (Andrijauskienè \& Dumčiuvienè, 2017). Individualism-Collectivism measures interdependence maintained by society among its citizens or members. IDV is high when privacy is respected, the reward is being given to individuals for their hardwork. IDV is low when people work for their goal not for the objective of the organization, harmony is maintained among group members and emphasis on establishing skills (Andrijauskienè \& Dumčiuvienè, 2017).

Collectivism focuses on interdependence. Individuals are not lonely but are independent and are committed, connected to an identical society or group. Societies with high IDV are not involved more in charitable activities. In US there is high IDV and is also involved in a lot of nonprofit activities. IDV has a positive relation with volunteering and giving behavior. Individuals act in a charitable manner since it aids their personal drives and thus should be inclined towards self-centered activities involved in individualistic values. In America, IDV explains the causes of inspiration to engage oneself in volunteering. Low inconsistency leads to a lack of connection between volunteering and IDV (Luria et al., 2015).

As compare to collectivism individualism's score of happiness is high because individuals focus on an individual's achievement and freedom whereas collectivism focuses on human relationships means this happiness is influenced by the valuation of other people (like neighbors, families and colleagues, etc.) (Dulababu, 2017).

\subsubsection{Culture and Institutions}

Culture has a direct relation with institutions, such as official legal and political institutions implied restrictions on a person's behavior. Culture is more sublime as compare to authorized and political institutions. Thus it can be said that culture might significantly influence the option of authorized and political institutions. Therefore it can be assumed that culture is a fundamental power underlying long term growth and official institutions (Gorodnichenko \& Roland, 2017). Miscommunication among different cultures had destroyed many businesses, 
hurt the reputation of many firms and might also harm the sales, etc. (Ansah, 2015).

The culture feature is basically a driver of an institution. If people are extremely motivated towards success and see the success of the economy as associated with deliberate selections then due to this they will work hard, capitalize for the forthcoming, will innovate and commence new initiatives regarding the economy. On the other hand, if people see success as achieve because of luck or to external factors then they will have a passive, lazy and resigned attitude related to the economy (Tabellini, 2010).

\subsection{Values}

Value is basically sharing thoughts, opinions, judgments, ideas about right and wrong and offers guidelines for a way of life and also guides about how to behave in various situations. Due to different values, everyone's consuming behavior and lifestyle vary from country to country. Values influence a person's behavior towards domestic and international goods and also affect a person's attitude (Dimitrova et al., 2016).

Value is something that directly or indirectly shared thoughts, ideas regarding what was right, wrong, bad, and good and should be provided as guidance for norms in different scenarios (Dimitrova et al., 2016).

Values are important and WVS (i.e. World Value Survey) tapped things that are tangible in the community. A vast civil good was recognized and the WVS scheme showed public strategy makers and academics. Yearly surveys consist of most of the people and countries data and make that data accessible free of cost and through this project, we had learned a lot about customs, ethnicity, etc. round the globe. Our main aim was to get people's attention on key traits of cross country comparison and to recover or improve our perception regarding values and its influence (Aleman \& Woods, 2015).

In the year 1997, Ronald Inglehart introduced the theory, showed that there are two value orientations one is the comparison between secular and traditional and other is the comparison between self-expression and survival orientation, basically provides meaning to a vast variety of behaviors and attitudes, views about life, family, religion, and marriage. Over the years world value survey has to turn out to be an important source for data in order to describe gender equality, democratization, interpersonal trust, etc. (Aleman \& Woods, 2015).

Secular versus traditional theory stated concepts regarding community and does they emphasize or deemphasize on traditional bases of authority like family, religion and nation's state. Whereas self-expression versus survival theory speaks about an individual's relation with society and does an individual prioritize conformity, autonomy, agency, and security. Secular value is basically a refined form of rational orientation while unrestricted values create a subgroup of self-assertiveness that emphasizes equal opportunities and freedom (Aleman \& Woods, 2015).

Micheal Bond along with his investigation group formed CVS (Chinese Value Survey), which regulates almost 2300 persons in 23 nations out of which 20 countries were overlapped with nations that were included in the IBM Survey and the outcomes revealed that Bond's 
dimensions were strongly correlated with Hofstede dimensions. In 1984 one more dimension (i.e long-run orientation) was added to the Hofstede index. In the year 2000 Inglehart led the European group to coordinate an enormous survey project known as WVS (World Value Survey) currently consists of 400,000 respondents of 100 nations. Data of WVS is available online (free of cost). In 2007 Minkov evaluate data of WVS in order to develop the latest value framework. Although each dimension was strongly correlated with all Hofstede dimensions except indulgence-restraint, which later on joined Hofstede index as the element or dimension (Whalen, 2016). The sub-variables of values that we have used in our study are the emotion of happiness, active/ inactive membership of a church or religious organization, important in life; religion, confidence on charitable/ humanitarian organization and active/ inactive membership of charitable/ humanitarian organization.

\subsubsection{Values and Happiness}

A lot of studies had been conducted on happiness and values. It was extensively observed that a negative connection was found between happiness and external values in nonwestern and western countries. Self-acceptance (intrinsic values), external values of popularity, image and economic success have an unfavorable relation with happiness in Japan, China, Peru, South Korea, the United States, and Germany. Viz. materialism (external values) has an unfavorable connection with well being, work and life satisfaction whereas viz. materialism has a positive linkage with anxiety and depression (Lee \&d Kawachi, 2019).

In comparison to materialism (i.e. a self-interested value) and like the measurement of group-oriented values (like society, family or religious values), self-enhancement that are advantageous for happiness or well being. Religious practice and values are also positively connected with happiness. Longitudinal research stated that when you prioritize your family over your leisure and work. This results in greater life satisfaction. When you prioritize money overtime then it is unfavorably connected with happiness (Lee \& Kawachi, 2019).

\subsection{Institutions}

Institutions are the most important components of a person's behavior due to which the performance of the economy gets affected (Leite et al., 2014). Institutions set limitations, boundaries or restrictions for behaviors and countries globally. Institution aids in policymaking and also affects the issues of the political economy. Those institutions that establish inducement structure for community increase efficiency and decrease uncertainty. For productive/ useful behavior effective institutions can restrict our actions and institutions that are efficient encourage growth (Asuquo, 2015).

Those countries that have good institutions and more protected asset rights with less distorted policies, will going to invest further in capital acquisition (i.e. human and physical assets). This will be utilized efficiently to accomplish a larger level of GDP per capita. Hence institutions (i.e. rules game in the world) are considered significant. Institutions basically set up society's incentive structure in order to increase efficiency and decrease uncertainty. For instance, if institutions are efficient, this can restrict our actions just to encourage productive behavior (Asuquo, 2015). 
An institution basically provides better governance, upgrades the standard of living and generates more and more opportunities for people of society (Asuquo, 2015).

According to neoclassical theory, institutions do not play an essential role because this theory recognizes various external factors of institutions that explained constraints like property rights, legal limits, were not the main causes for justification of development pathway across nations. The development and growth of a country depends on institutions includes structural models. These models assume that rational identical agents take decisions through increasing their utilities and earnings. This theory argues that institutions are understood and are factors which basically define several stability positions (Asuquo, 2015).

There are six world governance indicators (such as Political Stability, Regulatory Quality, Control of Corruption, Rule of Law, Accountability, and Voice and Government Effectiveness).

Accountability and Voice basically indicates the degree to which nation's people participate in the election, free mass media, liberty of communication and also consist of factors that measure different attributes of political rights and process and civil liberties. Accountability and Voice reflect citizen's participation regarding the selection of their government and freedom of media. Survey questions regarding accountability and voice includes do you trust the parliament, how much confident are you regarding the election's honesty, who are accountable of public officials (Apaza, 2009).

Accountability and Voice show procedures of the government's monitoring, election, and replacement (Ahmad \& Saleem, 2014). When women and men both participate this indicates freedom regarding expression and association and also shows a structured civil society (Kilishi et al., 2013).

Accountability and voice measure attributes of political rights and shows freedom regarding expression. There are numerous theories that show the impact of political differences on charitable giving. Political freedom and democracy affect charitable behavior since the government put lesser limitations on charitable firms. Due to lesser restrictions on profit firms solicit more funds (Einolf, 2017).

Political Stability indicates the probability that the government would get damaged or conquered by illegal means which includes terrorism, etc. Political Stability measures political instability or stability of the country. Survey questions related to political stability include how much you would rate security risk, a threat by a terrorist would significantly affect businesses and external sources of governmental risk (Apaza, 2009). This indicator also measures how the government monitored, replaced and elected (Ahmad and Saleem, 2014).

Government Effectiveness shows the worth of public service, the significance of policy creation, execution and freedom from political forces, trustworthiness and reliability of government obligation. Government Effectiveness reflects policy implementation and formulation by the government and also shows the quality of public and civil services. Survey questions about government effectiveness consist of how much telecommunication 
affect business's growth, bureaucratic delays and government's economic guidelines do not adjust quickly according to alterations in the economy (Apaza, 2009).

It also contains the government's response towards issues that involves that all the investors should be assisted within a sound time period. In short, it can be said that this factor shows the government's capability to implement and design policies (Ahmad \& Saleem, 2014).

Government effectiveness shows subjective assessments of bureaucracy's quality, the government's credibility towards policy's commitment, etc. Corruption shows the subjective evaluation of the part of bribery etc that affects political decisions (Einolf, 2017).

Regulatory Quality, this dimension shows the government's capability to make and implement better policies and rules that permit and endorse private companies' progress. Regulatory Quality reflects the implementation and formulation of sound regulations and policies for the private sector. Survey questions that were asked in regulatory quality are related to competition, price liberalization and protectionism in the nation pessimistically influence business activities (Apaza, 2009).

This dimension also shows how effectively government exercise and formulate policies (Ahmad \& Saleem, 2014).

Rule of Law, this factor indicates that agents assure and also stand by the societal rules. Rule of Law reflects how much agents stand by society's rules (Ahmad \& Saleem, 2014). Survey questions asked in rule of law are related to accountability, trust, and confidence on court system (Apaza, 2009).

Particularly contract enforcement quality, courts, police, violence, and crime. This dimension focuses on situations related to institutions and citizen's respect that govern social and economic relations between them (Ahmad \& Saleem, 2014).

Corruption indicates people's power for personal benefit which contains both of them; grand as well as petty kinds of corruption (Ahmad \& Saleem, 2014). Corruption measures the use of public power for personal interest. Survey questions related to corruption consist of transparency and accountability in rural and political risk's inner sources (Apaza, 2009).

Government effectiveness and corruption has a positive linkage with charitable behavior because due to the effective government it would not be difficult for charitable firms to accomplish legal status and due to noncorrupt government charitable organizations would be capable to develop and ask for donations excluding transaction cost (i.e. sort of government's harassment and bribe).

\subsubsection{Institutions and Happiness}

There are numerous theories that shows the connection between happiness and institution. Due to good governance, people are more happier because good government directly improves living standards or indirectly allows people to accomplish something of a higher level that has a direct linkage with their happiness. Due to lack of corruption efficiency of private and public enterprise increases and therefore generate encouraging situations for the 
growth of economy. Various evidence indicates that due to the greater level of trust people are more happier(Helliwell et al., 2018)

When countries become wealthier their degree of happiness decreases since an increase in income increases material norms. Whereas middle-income nations showed little connection between well-being and growth. Regulatory quality, corruption, government effectiveness, and law rules add value directly towards happiness. Better governance affects contact's quality among the nation's citizens (Helliwell et al., 2018).

Due to an increase in the level of trust, the degree of happiness in society also increases. Trustworthiness gets affected by the quality or features of government institutions. Enhancements in the quality of institutions increase social trust (Helliwell et al., 2018).

\subsection{Happiness}

Happiness is an emotion, feeling and is related to well being and life satisfaction. Happiness is basically free from disabilities, illness, and suffering, being cared for or respected, free from hardships, tensions, and worries, living a joyful and carefree life, possess a normal and healthy mind. The meaning of happiness is complex and ambiguous and happiness varies from nation to nation. Happiness is something that governs optimistic over a pessimistic approach (Dulababu, 2017).

Happiness can be defined as the feeling or situation of mind. But according to philosophical and religious perspective happiness is depicted as the situation of being comfortable, healthy, wealthy and happy. There are two kinds of happiness; one is mental happiness another is physical happiness. Physical happiness was referred to as happiness resulting from 5 sensations such as olfactory, tactile, visual, gustatory and auditory. Mental happiness is something that arises from cognitive satisfaction, pleasure, and delight (Pholphirul, 2015).

A lot of countries emphasize more and more on happiness since it's a pathway to economic attainability. Due to this, a variety of studies' objective was to describe the association among components that contribute to happiness. The list of components consists of unemployment status, education, health condition, income, urbanization, and marital status. Though happiness lies within the people's mind and gets affected by a variety of cultures and values across various countries (Pholphirul, 2015).

In the year 1998 Schyns introduced two theories related to happiness, namely comparison theory and Maslows' needs theory. According to comparison theory happiness of people largely relies on comparisons among circumstances of perceived life and quality of life. Comparison theory stated that materialistic needs do not contribute much to happiness. Although happiness does not gets affected due to the rise in income. In accordance with needs theory, materialistic needs can be satisfied easily but the influence of satisfaction on happiness is inadequate. Moreover at greater religious level satisfaction is unlimited (Ye et al., 2015).

Maslow's theory stated that a good life can be obtained by satisfying the needs. This means that a person will be happier if his or her needs were satisfied. There are different types of 
needs, at a basic level needs for the purpose of survival consists of food. At the next level safety and physiological needs are required like stability, anxiety, security, fearlessness, etc. Then esteem needs are required like fame, glory, reputation, prestige, etc. Maslow also stated that higher need satisfaction shows more attractive results (such as more peacefulness, happiness and inner life richness). Comparison and needs theory proposed that materialistic and economic satisfactions are easily obtainable (Ye et al., 2015)

Happiness index includes generosity, social support, freedom regarding life's decision, etc. Social support, someone you can always count on whenever you are in trouble. Freedom related to life's decision is basically the person's level of satisfaction and dissatisfaction regarding freedom to make decisions about one's life. Generosity, basically measured donations (Helliwell et al., 2018).

\subsection{Philanthropy}

Philanthropy is voluntarily improving people's well-being and it's an action that is taken for the benefit of others. Basically, it's a voluntary contribution. Philanthropy abolishes social problems. The most common behavior of philanthropy is a monetary donation. Monetary donation can be in the form of resources, cash or time provided to nonprofit firms (Hassan et al, 2018). Philanthropic aid can be given with the help of an intermediary or directly that eases philanthropic investments and donations. Intermediaries include federated donors that gathered contributions and distribute them to nonprofit firms. Philanthropy's financial contributions are gathered from four sources such as corporate foundations, an estate from individuals, living individuals and funding by individuals (Phillips and Jung, 2016).

Philanthropy is basically an aid that is willingly provided to help society. Charity, voluntarily improves people's well being. We can say that philanthropy is an individual work or act conducted for the interest of society (Hassan et al., 2018).

CAF index can be defined as the mixture of volunteering, helping strangers and donating money (Smith, 2015).

People who involve themselves in the activity of volunteering have good mental and physical health, low mortality rate and also are healthy. They are less depressive and more happy. Whereas linkage between emotion of happiness (i.e proxy of value) and volunteering is strong, issues like excluded variable unfairness, self-selection, and inverse causation most of the time remains unsolved. The core characteristics due to which people choose themselves in non-volunteering and volunteering groups can also be related to self-selection. Volunteering leads to greater well-being and thus inverse is possible. Individuals who feel good or well engage themselves more in volunteering (i.e. reverse causation) (Borgonovi, 2008).

Correlation can be due to changes in conditions that determine both choices i.e. to begin volunteering and greater well being. When investigations were done on the linkage between well being and volunteering in different time periods to build people's heterogeneity, causation and self-selection remain unsolved. One of the investigations revealed the relation between well being and social context and use variables that are instrumental in order to resolve unsettled issues (Borgonovi, 2008). 


\section{Country Analysis}

Following data was acquired from panel study and we have taken only CAF, WGI and HAP because rest of the variables panel data was not available.

Table 1. Country Analysis

\begin{tabular}{|c|c|c|c|}
\hline Country & CAF & WGI & HAP \\
\hline Afghanistan & 1.760 & -8.901 & -7.964 \\
\hline Albania & 0.940 & -1.193 & -5.878 \\
\hline Armenia & 1.060 & -1.580 & -9.041 \\
\hline Australia & 2.860 & 8.454 & 8.379 \\
\hline Austria & 2.290 & 7.984 & 5.975 \\
\hline Belarus & 1.320 & -4.936 & -1.615 \\
\hline Bangladesh & 1.240 & -4.915 & -5.781 \\
\hline Belgium & 1.740 & 7.017 & 3.572 \\
\hline Bulgaria & 0.870 & 0.693 & -3.849 \\
\hline Canada & 2.860 & 8.544 & 7.803 \\
\hline Czech Republic & 1.260 & 4.672 & 0.280 \\
\hline Colombia & 1.870 & -1.678 & 1.869 \\
\hline Chile & 1.900 & 6.262 & 1.527 \\
\hline Denmark & 2.280 & 9.433 & 7.679 \\
\hline Ecuador & 1.070 & -4.003 & -1.456 \\
\hline Egypt & 1.170 & -4.503 & -7.794 \\
\hline El Salvador & 1.180 & -0.811 & -3.021 \\
\hline Finland & 2.090 & 9.798 & 5.413 \\
\hline France & 1.460 & 6.252 & 2.055 \\
\hline Greece & 0.740 & 1.548 & -9.044 \\
\hline Germany & 2.100 & 7.800 & 4.912 \\
\hline Ghana & 1.840 & 0.108 & -1.904 \\
\hline Indonesia & 2.200 & -2.279 & 4.511 \\
\hline Italy & 1.720 & 2.533 & -1.785 \\
\hline India & 1.170 & -1.925 & -4.726 \\
\hline Israel & 1.940 & 3.424 & 1.381 \\
\hline Kenya & 2.010 & -3.749 & 0.004 \\
\hline
\end{tabular}


Lebanon

1.620

$-3.851$

$-3.557$

Mali

1.130

$-3.999$

$-1.658$

Malaysia

1.710

1.705

1.913

Mexico

1.490

$-1.049$

$-1.123$

Nepal

1.480

$-4.735$

$-2.609$

Netherlands

2.680

8.905

7.939

New Zealand

2.870

9.567

8.176

Pakistan

1.510

$-6.172$

$-9.538$

Panama

1.730

0.298

2.392

Paraguay

1.800

$-3.563$

3.043

Peru

1.370

$-1.353$

$-2.219$

Philippiness

2.090

$-2.193$

2.512

Poland

1.340

4.304

2.362

Portugal

1.180

4.860

0.067

Romania

1.040

0.475

$-4.601$

Russian Federation

0.950

$-4.150$

$-3.559$

Srilanka

2.530

$-2.031$

3.132

Serbia

0.830

$-0.764$

$-6.540$

Slovakia

1.270

3.810

$-0.964$

Slovenia

1.910

4.633

4.327

Spain

1.510

4.454

1.418

Sweden

1.920

9.453

6.639

Tanzania

1.600

$-2.597$

$-1.056$

Thailand

2.190

$-1.738$

8.202

Tunisia

1.260

$-1.487$

$-7.461$

Tajikistan

1.790

$-6.449$

$-1.312$

United Kingdom

2.730

7.423

7.910

Uganda

1.760

$-3.431$

1.095

Ukraine

1.070

$-3.795$

$-3.986$

United States

2.970

6.564

5.214

Uruguay

1.420

4.080

2.470

Venezuela

1.080

$-7.409$

$-1.310$ 


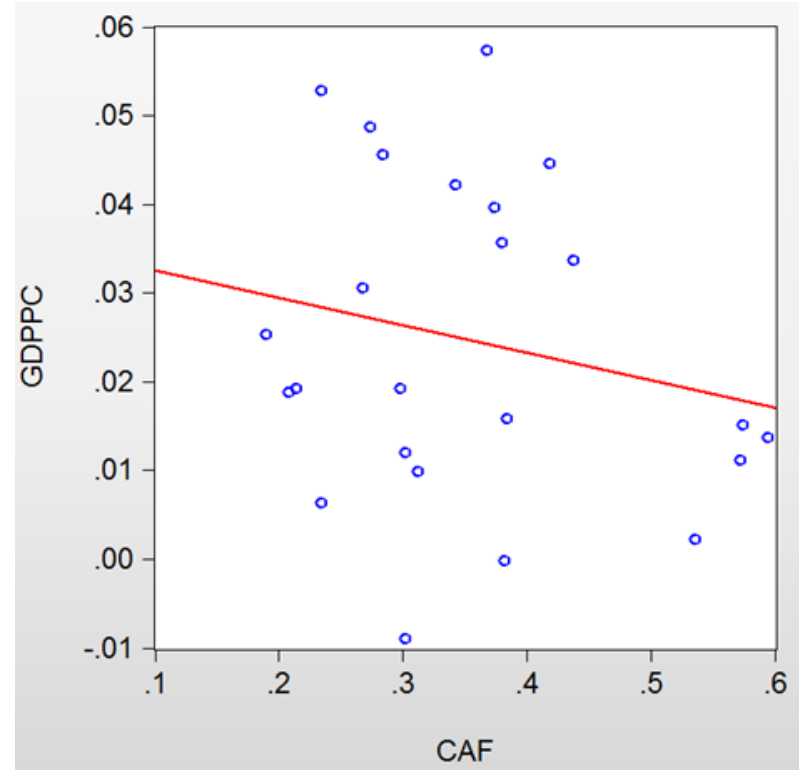

Graph I

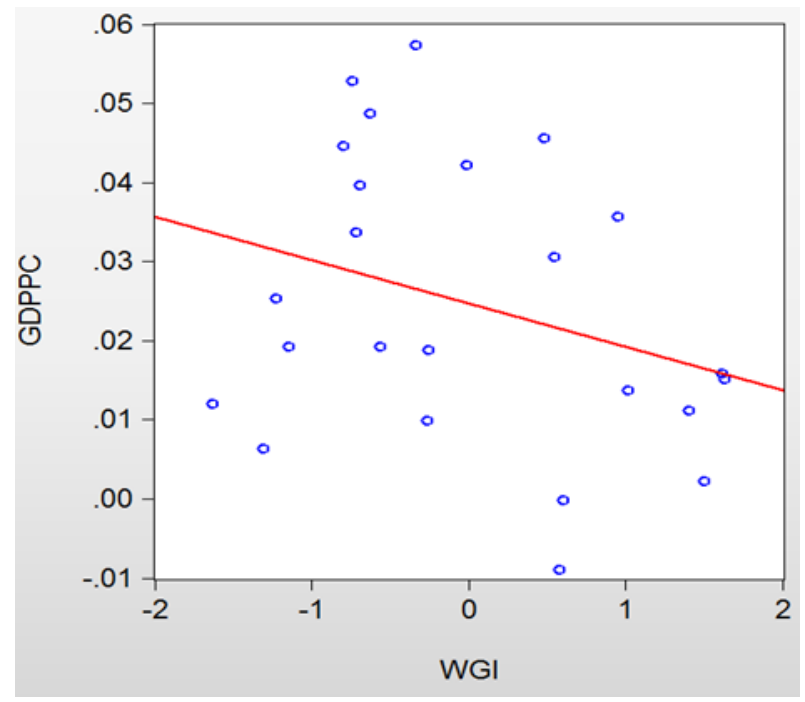

Graph III

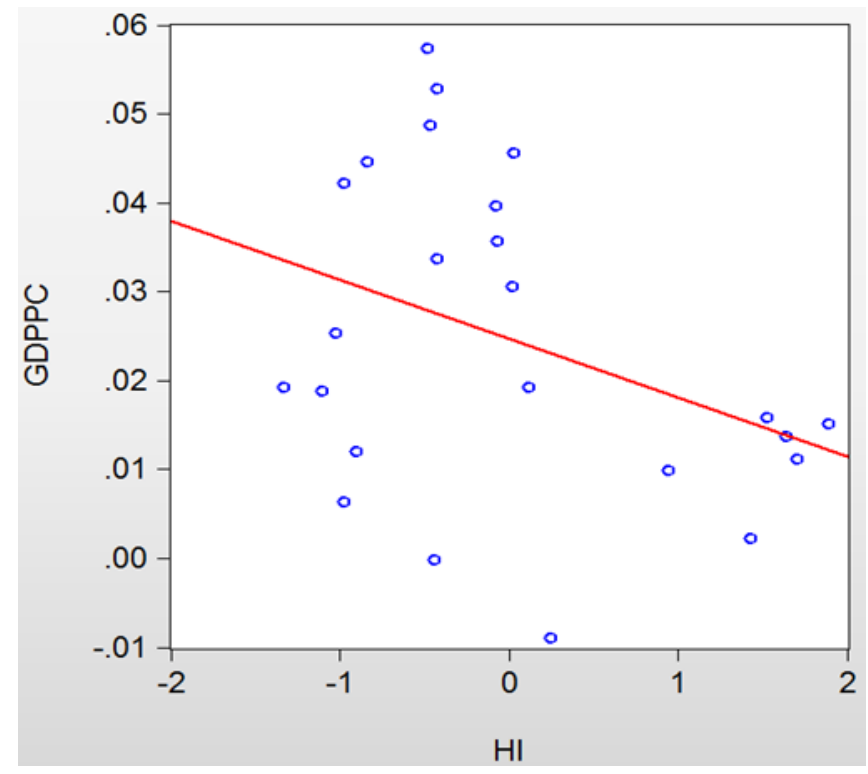

Graph II

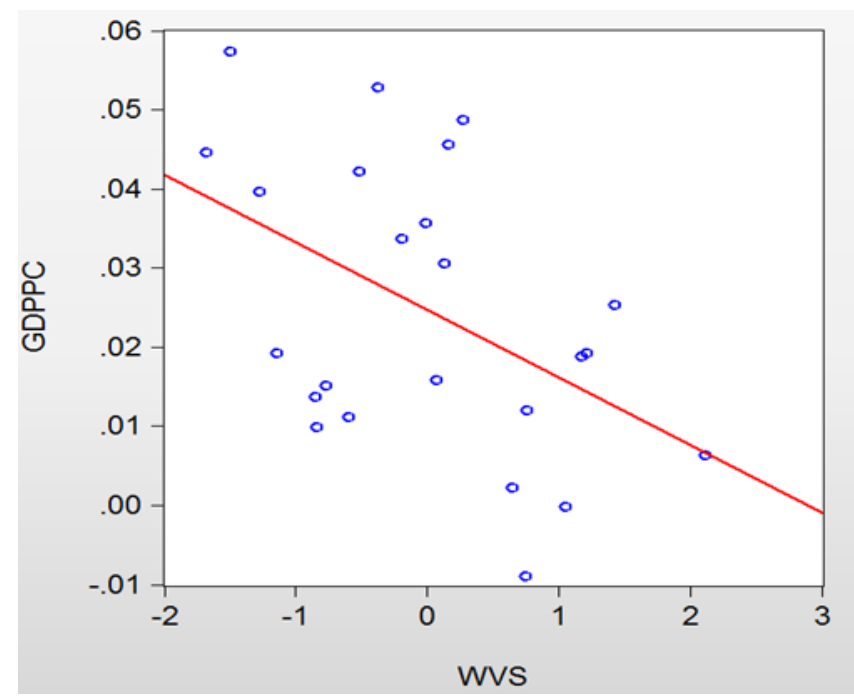

Graph IV 


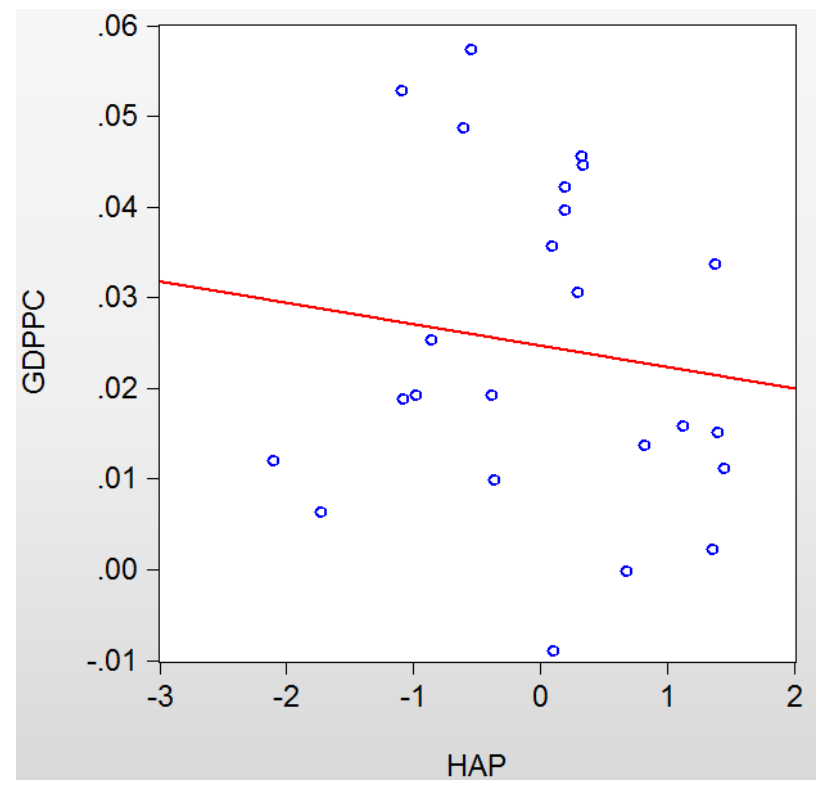

Graph V

The above graphs consist of cross-sectional data from 24 countries. In graph I CAF (charitable aid foundation giving index) is on $\mathrm{x}$-axis while Real GDP per capita (GDPPC) is on y-axis and Ghana $(0.37,0.057)$, Slovenia $(0.38,-0.000)$, Spain $(0.30,-0.009)$, India $(0.23$, $0.053)$ and Netherlands $(0.54,0.002)$ are outliers because they are far away from regression line and relation between CAF and GDPPC is moderately strong and positive. In graph II HI (Hofstede Index) is on the x-axis and GDPPC is on the y-axis. Spain (0.2, -0.009), Slovenia $(0.4,-0.000)$, Ghana $(-0.5,0.057)$ and India $(-0.4,0.053)$ are outliers because they are distant from the regression line and relation between $\mathrm{HI}$ and GDPPC is moderately strong and positive.

In graph III WGI (World Governance indicator) is on the x-axis and GDPPC is on the y-axis. Spain (0.6, -0.009), Slovenia (0.6, -0.000), Ghana (-0.3, 0.057) and India (-0.7, 0.053) are outliers because they are distant from the regression line and relation between WGI and GDPPC is moderately strong and positive. In graph IV WVS (World Value Survey) is on the $\mathrm{x}$-axis and GDPPC is on the y-axis. Spain (0.7, -0.009), Peru $(0.3,0.049)$, Ghana $(-1.5,0.057)$ and India $(-0.4,0.053)$ are outliers because they are far away from the regression line and relation between WVS and GDPPC is moderately strong and positive. In graph V HAP (Happiness Index) is on the $\mathrm{x}$-axis while GDPPC is on the $\mathrm{y}$-axis and Ghana $(-0.5,0.057)$, India (-1.1, 0.053), Spain $(0.1,-0.009)$ and Peru $(-0.6,0.049)$ are outliers because they are far away from the regression line and relation between HAP and GDPPC is moderately strong and positive.

\section{Methodology}

In this section we will discuss sampling, sources of data, statistical tools, framework, hypotheses, etc. related to our topic. 


\subsection{Sampling}

In our research, there are two types of data; panel and cross-sectional. For the panel, we have gathered data from the WGI, happiness index and CAF index of 62 countries. Whereas for cross-sectional we have acquired data from Hofstede index, WVS, WGI, happiness index and CAF index of 24 countries. Panel Data was collected from the period 2010 to 2014 (i.e. 5 years) and a convenience sampling technique is used.

\subsection{Data Source and Collection}

Data for the research was acquired from secondary sources (like Hofstede Index, World Value Survey, World Governance Indicators, Happiness Index and CAF World Giving Index).

Hofstede Index is an indicator that shows the features of a culture. There are six dimensions of a culture such as Individualism-Collectivism (IDV), Power distance (PDI), Indulgence-Restraint (IVR), Masculinity-Femininity (MAS), Uncertainty Avoidance (UAI) and Long and Short-run Orientation (ITOWVS) (Andrijauskienė \& Dumčiuvienė, 2017).

The range of the score is from 0 (minimum value) to 100 (maximum value) (Andrijauskienè $\&$ Dumčiuvienè, 2017). Hofstede index shows cross-sectional data of more than 50 countries and the data was retrieved from websites like geerthofstede.com and Hofstede insights.

World Value Survey (WVS) is an indicator that measures political, social and cultural changes in the globe (Dimitrovaet al., 2016). The data for WVS is collected by surveying more than 100 countries. WVS study is held in waves and each wave contains a five-year time span. There are 6 waves; wave 1 (1981 to 1984), wave 2 (1990 to 1994), wave 3 (1995 to 1998), wave 4 (2000 to 2004), wave 5 (2005 to 2009) and wave 6 (2010 to 2014). The interview is conducted with more than 400000 respondents to collect data. In interview questions related to values, beliefs, democratization, gender equality, well being, religion, economic development, and social capital were asked by the respondents.

The indicators that we have used in this research are feeling of happiness (V10) and scale range is from 1 (very happy) to 4 (not at all happy), active/ inactive membership of church or religious organization (V25) and active/ inactive membership of charitable/ humanitarian organization (V32); both of these variables scale ranges from 0 (not a member) to 2 (active member), important in life; religion (V9)and scale range is from 1 (very important) to 4 (not at all important), confidence on charitable/ humanitarian organization (V124) and range is from 1 (a great deal) to 4 (none at all).

Confidence on charitable/ humanitarian organization, it shows how much people trust a charitable organization (Wiepking, 2010). Important in life; religion, it shows how much religion is important in your life (Matei \& Abrudan 2018). The emotion of happiness, feeling good or happy (Musikanski et al., 2017).

Active/ inactive membership of church or religious organization, how much actively or inactively an individual takes part in religious or church-related activities. Active/ inactive membership of charitable/ humanitarian organization, how much actively or inactively an individual takes part in charitable activities. The cross-sectional data was available in six 
waves as mentioned above but for our study, we have taken data from wave 6 (i.e. 2010 to 2014) and is retrieved from http://www.worldvaluessurvey.org/wvs.jsp.

World Governance Indicator (WGI) is an indicator that shows the features of an institution. There are six indicators of institutions such as rule of law, corruption, regulatory quality, accountability and voice, political stability and government effectiveness.

All of the governance indicators are measured by governance estimate. The range of the estimate is from -2.5 to $2.5,-2.5$ is weak and 2.5 is strong. If the value of the indicator is positive this means that the condition of that dimension is good in the nation and if the value is negative then this shows, the situation of that dimension is not good (Ahmad \& Saleem, 2014).

WGI is a compound data. Data for WGI was acquired by surveying many individuals and firms and by assessing rating agencies, multilateral agencies, and non-governmental firms. WGI data was available of 214 countries from the year 1996 to 2017 and the data of more than three hundred variables were issued by more than thirty firms that measure WGI (Apaza, 2009). The data for WGI was retrieved from info.worldbank.org/governance/wgi/.

Happiness Index is an indicator used by policymakers, researchers and the community to enhance and understand one's well-being and happiness (Musikanski et al, 2017).Social support, generosity, GDP per capita, healthy life, corruption and freedom to make decisions were sub-indices of happiness index.

The happiness index gathered its data from Gallup World Poll (GWP), Gallup interviews 1000 people in more than 100 countries each year and respondents are selected randomly but the individual's age limit is 15 years or older and these people are asked the same questions as discussed below.

Social Support, helping someone in their difficult or problematic times and contributing towards the well being of the nation. Healthy life; the number of a healthy period a person is expected to live.Generosity, being generous and kind to someone and willingly donating money to help others and freedom of choice, the freedom that is giving to people regarding their life decisions (Dulababu, 2017).

Gallup World Poll includes survey questions regarding social support, generosity, GDP per capita, healthy life, corruption and freedom to make decisions that are mentioned as follows; Social support is measured by asking people if you are in problem, is there anyone you can count on in your difficult times. GDP per capita; the value of services and goods of a country and measured by national government statistical agency. A healthy life is calculated by different 100 health factors. Whereas freedom of choice is measured by asking people their satisfaction and dissatisfaction regarding freedom to decide what you want to do in your life. Generosity is indicated by asking did you donate money in the last month. Corruption is measured by asking individuals; is corruption involved largely in every aspect of business or government.

The range of the score is from 0 (minimum value) to 100 (maximum value). The data was 
available from the year 2005 to 2017 of more than 100 countries on the website https://www.Online-data-for-chapter-2-whr-2016.xlsx

CAF World Giving Index measures giving behavior from country to country and it is a combination of volunteering, helping and donation (Smith, 2015).

Volunteering is basically a selfless action where society or individuals offersservices without expecting anything in return (Wilson, 2000). Donation is basically human aid and it can be in any form like giving money, clothes or food generously to organizations or individuals. Helping someone or stranger voluntarily because your actual don't know who needs help.

The donation, volunteering and helping a stranger is measured with of Gallup World Pollin which you ask people did you donate money, volunteer and help strangers in the last month. The range of the score is from 0 (minimum value) to 100 (maximum value). The data was available from the period 2010 to 2018 of more than 100 countries and was retrieved from cafonline.org.

\subsection{Statistical Tools and Techniques}

In this research we have used SPSS version 22 (only for factor analysis) and E-Views version 7. The perspective of the study was to find out the influence on World's Philanthropy by Culture, Value, Institutions, and Happiness. The statistical tools that were applied in this research are correlation, descriptive statistics, and regression.

\subsection{Factor Analysis}

Factor analysis is a tool that reduces large no of factors into small no of factors and is used to find out the possible no. of factors that cause scale structure with help of varimax rotation and a principal component. Factor analysis reduces dimensions of data and the data was assessed with the help of KMO (Kaiser Meyer Olkin), which shows sampling adequacy and 0.6 is the least accepted value and Bartlett's test shows significany if P-value is less than 0.05 Howard, (2016).

We have done the factor analysis of all the indicators of WGI (consists of Voice and Accountability, Political Stability, Government Effectiveness, Regulatory Quality, Rule of Law and Corruption) (in the panel data) because there is a high and strong positive correlation among all the indicators of WGI (World Governance Indicators) since all the values in the correlation table $I$ is greater than 0.7 , this means that there is a high multicollinearity.

We have done the factor analysis of all the indicators of WGI (in the cross-sectional data) because high and strong positive correlation was found among all WGI factors in the correlation table II as their value is greater than 0.7 this shows that there is a high multicollinearity and our number of observation is also small (i.e. of only 24 countries).

In cross-sectional data we have also done the factor analysis of all the indicators of Hofstede index (consists of Power Distance, Individualism-Collectivism, Masculinity-Femininity, Uncertainty Avoidance Index, Long-Run Orientation and Short-Run Orientation and 


\section{Macrothink}

International Journal of Social Work

ISSN 2332-7278 2020, Vol. 7, No. 1

Indulgence-Restraint), world value survey (includes Active or Inactive Membership of Charitable Humanitarian Organization, Active or Inactive Membership of Church or Religious Organization, Importance of Religion in Life, Confidence on Charitable Humanitarian Organization and Feeling of Happiness) and Happiness index (includes Social Support, Generosity, and Freedom to make decisions), because our number of observations are small (i.e. of only 24 countries) due to our study, was showing inappropriate results.

\subsection{Framework}

\section{INDEPENDENT VARIABLE}

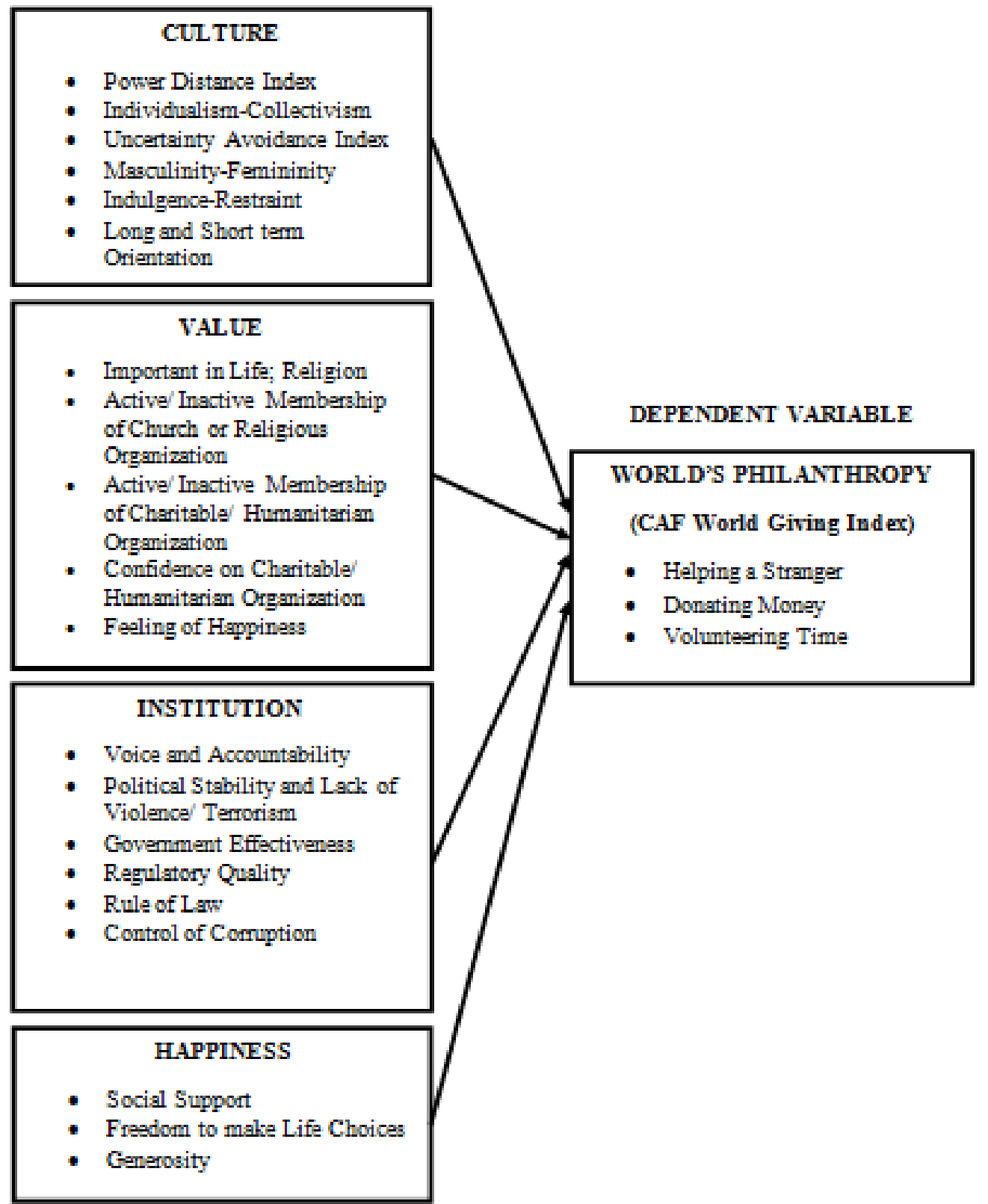

\section{Data Analysis}

In this section, we will analyze the panel and cross-sectional data with the help of correlation, 
descriptive statistics, and regression.

\subsection{Correlation Analysis}

Table 2. Correlation (Panel Data)

\begin{tabular}{lllllllllll}
\hline & CAF & VA & PS & GE & RQ & RL & CC & SS & FLC & GEN \\
\hline CAF & 1.00 & 0.42 & 0.33 & 0.55 & 0.51 & 0.56 & 0.54 & 0.39 & 0.64 & 0.77 \\
VA & 0.42 & 1.00 & 0.80 & 0.90 & 0.90 & 0.89 & 0.91 & 0.54 & 0.56 & 0.28 \\
PS & 0.33 & 0.80 & 1.00 & 0.79 & 0.77 & 0.80 & 0.80 & 0.66 & 0.52 & 0.11 \\
GE & 0.55 & 0.90 & 0.79 & 1.00 & 0.95 & 0.95 & 0.97 & 0.60 & 0.62 & 0.35 \\
RQ & 0.51 & 0.90 & 0.77 & 0.95 & 1.00 & 0.91 & 0.95 & 0.57 & 0.55 & 0.34 \\
CC & 0.56 & 0.89 & 0.80 & 0.95 & 0.91 & 1.00 & 0.97 & 0.59 & 0.64 & 0.37 \\
RL & 0.54 & 0.91 & 0.80 & 0.97 & 0.95 & 0.97 & 1.00 & 0.57 & 0.60 & 0.36 \\
SS & 0.39 & 0.54 & 0.66 & 0.60 & 0.57 & 0.59 & 0.57 & 1.00 & 0.55 & 0.19 \\
FLC & 0.64 & 0.56 & 0.52 & 0.62 & 0.55 & 0.64 & 0.60 & 0.55 & 1.00 & 0.45 \\
GEN & 0.77 & 0.28 & 0.11 & 0.35 & 0.34 & 0.37 & 0.36 & 0.19 & 0.45 & 1.00 \\
\hline
\end{tabular}

Table 2 shows the analysis of correlation. In panel data World Governance Indicators (includes Voice and Accountability (VA), Political Stability (PS), Government Effectiveness (GE), Regulatory Quality (RQ), Control of Corruption (CC), Rule of Law (RL)), Social Support (SS), Freedom of Life Choices (FLC) and Generosity (GEN) are the independent variables whereas Charitable Aid Foundation Index (CAF) is the dependent variable. CAF has a moderate relation with VA, PS, GE, RQ, CC, RL, SS and FLC having values of 0.42 , $0.33,0.55,0.51,0.56,0.54,0.39$ and 0.64 while CAF has a strong relation with GEN having value of 0.77 .

Table 3. Correlation (Cross Sectional Data)

\section{CAF PDI IDV MAS UAI ITOWVS IVR AICH AICR IILR CCH FOH VA PS GE RQ CC RL SS FLC GEN}

\begin{tabular}{llllllllllllllllllllllllllllll}
\hline CAF & 1.00 & -0.66 & 0.60 & 0.06 & -0.56 & -0.28 & 0.60 & 0.77 & 0.32 & 0.34 & -0.15 & -0.42 & 0.57 & 0.46 & 0.75 & 0.70 & 0.69 & 0.70 & 0.45 & 0.66 & 0.81 \\
PDI & -0.66 & 1.00 & -0.6 & 0.10 & 0.34 & 0.15 & -0.40 & -0.55 & -0.09 & -0.53 & -0.22 & 0.12 & -0.63 & -0.45 & -0.65 & -0.68 & -0.74 & -0.71 & -0.37 & -0.38 & -0.55 \\
IDV & 0.60 & -0.69 & 1.00 & 0.09 & -0.49 & 0.12 & 0.33 & 0.62 & 0.03 & 0.57 & 0.09 & -0.13 & 0.66 & 0.64 & 0.74 & 0.69 & 0.71 & 0.75 & 0.49 & 0.50 & 0.37 \\
MAS & 0.06 & 0.10 & 0.09 & 1.00 & -0.11 & -0.48 & 0.09 & 0.32 & 0.44 & -0.50 & -0.52 & -0.22 & -0.21 & -0.27 & -0.19 & -0.17 & -0.27 & -0.25 & -0.19 & -0.03 & -0.14 \\
UAI & -0.56 & 0.34 & -0.49 & -0.11 & 1.00 & 0.12 & -0.35 & -0.68 & -0.32 & 0.09 & 0.19 & 0.41 & -0.21 & -0.13 & -0.46 & -0.31 & -0.33 & -0.38 & 0.05 & -0.41 & -0.57 \\
ITOWVS & -0.28 & 0.15 & 0.12 & -0.48 & 0.12 & 1.00 & -0.40 & -0.28 & -0.58 & 0.42 & 0.56 & 0.06 & -0.03 & 0.04 & -0.03 & -0.10 & -0.08 & -0.03 & 0.12 & -0.22 & -0.15 \\
IVR & 0.60 & -0.40 & 0.33 & 0.09 & -0.35 & -0.40 & 1.00 & 0.63 & 0.66 & 0.29 & -0.34 & -0.64 & 0.54 & 0.50 & 0.65 & 0.65 & 0.56 & 0.52 & 0.47 & 0.72 & 0.34 \\
AICH & 0.77 & -0.55 & 0.62 & 0.32 & -0.68 & -0.28 & 0.63 & 1.00 & 0.49 & 0.20 & -0.22 & -0.49 & 0.48 & 0.37 & 0.63 & 0.55 & 0.52 & 0.52 & 0.37 & 0.66 & 0.53 \\
AICR & 0.32 & -0.09 & 0.03 & 0.44 & -0.32 & -0.58 & 0.66 & 0.49 & 1.00 & -0.33 & -0.49 & -0.51 & 0.11 & 0.04 & 0.08 & 0.10 & 0.01 & 0.00 & -0.02 & 0.32 & 0.05 \\
IILR & 0.34 & -0.53 & 0.57 & -0.50 & 0.09 & 0.42 & 0.29 & 0.20 & -0.33 & 1.00 & 0.33 & -0.05 & 0.69 & 0.69 & 0.67 & 0.65 & 0.72 & 0.69 & 0.71 & 0.46 & 0.18
\end{tabular}




$\begin{array}{lllllllllllllllllllllllllllllllllll}\text { CCH } & -0.15 & -0.22 & 0.09 & -0.52 & 0.19 & 0.56 & -0.34 & -0.22 & -0.49 & 0.33 & 1.00 & 0.38 & -0.06 & 0.03 & -0.02 & 0.03 & 0.01 & 0.04 & 0.05 & -0.36 & -0.07 \\ \text { FOH } & -0.42 & 0.12 & -0.13 & -0.22 & 0.41 & 0.06 & -0.64 & -0.49 & -0.51 & -0.05 & 0.38 & 1.00 & -0.31 & -0.14 & -0.38 & -0.31 & -0.22 & -0.20 & -0.16 & -0.56 & -0.40 \\ \text { VA } & 0.57 & -0.63 & 0.66 & -0.21 & -0.21 & -0.03 & 0.54 & 0.48 & 0.11 & 0.69 & -0.06 & -0.31 & 1.00 & 0.85 & 0.84 & 0.85 & 0.90 & 0.89 & 0.49 & 0.70 & 0.41 \\ \text { PS } & 0.46 & -0.45 & 0.64 & -0.27 & -0.13 & 0.04 & 0.50 & 0.37 & 0.04 & 0.69 & 0.03 & -0.14 & 0.85 & 1.00 & 0.82 & 0.83 & 0.86 & 0.86 & 0.66 & 0.67 & 0.26 \\ \text { GE } & 0.75 & -0.65 & 0.74 & -0.19 & -0.46 & -0.03 & 0.65 & 0.63 & 0.08 & 0.67 & -0.02 & -0.38 & 0.84 & 0.82 & 1.00 & 0.94 & 0.94 & 0.96 & 0.65 & 0.78 & 0.58 \\ \text { RQ } & 0.70 & -0.68 & 0.69 & -0.17 & -0.31 & -0.10 & 0.65 & 0.55 & 0.10 & 0.65 & 0.03 & -0.31 & 0.85 & 0.83 & 0.94 & 1.00 & 0.93 & 0.93 & 0.65 & 0.71 & 0.53 \\ \text { CC } & 0.69 & -0.74 & 0.71 & -0.27 & -0.33 & -0.08 & 0.56 & 0.52 & 0.01 & 0.72 & 0.01 & -0.22 & 0.90 & 0.86 & 0.94 & 0.93 & 1.00 & 0.98 & 0.58 & 0.69 & 0.54 \\ \text { RL } & 0.70 & -0.71 & 0.75 & -0.25 & -0.38 & -0.03 & 0.52 & 0.52 & 0.00 & 0.69 & 0.04 & -0.20 & 0.89 & 0.86 & 0.96 & 0.93 & 0.98 & 1.00 & 0.57 & 0.67 & 0.56 \\ \text { SS } & 0.45 & -0.37 & 0.49 & -0.19 & 0.05 & 0.12 & 0.47 & 0.37 & -0.02 & 0.71 & 0.05 & -0.16 & 0.49 & 0.66 & 0.65 & 0.65 & 0.58 & 0.57 & 1.00 & 0.63 & 0.18 \\ \text { FLC } & 0.66 & -0.38 & 0.50 & -0.03 & -0.41 & -0.22 & 0.72 & 0.66 & 0.32 & 0.46 & -0.36 & -0.56 & 0.70 & 0.67 & 0.78 & 0.71 & 0.69 & 0.67 & 0.63 & 1.00 & 0.48 \\ \text { GEN } & 0.81 & -0.55 & 0.37 & -0.14 & -0.57 & -0.15 & 0.34 & 0.53 & 0.05 & 0.18 & -0.07 & -0.40 & 0.41 & 0.26 & 0.58 & 0.53 & 0.54 & 0.56 & 0.18 & 0.48 & 1.00\end{array}$

Table 3 shows the analysis of correlation. In cross-sectional data Power Distance (PDI), Individualism-Collectivism (IDV), Masculinity-Femininity (MAS), Uncertainty Avoidance Index (UAI), Long-Run Orientation-Short-Run Orientation (ITOWVS) and IndulgenceRestraint (IVR), Active or Inactive Membership of Charitable Humanitarian Organization(AICH), Active or Inactive Membership of Church or Religious Organization (AICR), Importance of Religion in Life (IILR), Confidence on Charitable Humanitarian Organization ( $\mathrm{CCH}$ ) and Feeling of Happiness (FOH),VA, PS, GE, RQ, CC, RL, SS, FLC, and GEN are the independent variables whereas CAF is the dependent variable. CAF has a moderate relation with PDI, IDV, UAI, IVR, AICR, IILR, FOH, VA, PS, RQ, CC, RL, SS, FLC having values of $-0.66,0.60,-0.56,0.60,0.32,0.34,-0.42,0.57,0.46,0.70,0.69,0.70$, 0.45 and 0.66 while CAF has strong relation with $\mathrm{AICH}, \mathrm{GE}$ and GEN having values of 0.77 , 0.75 and 0.81 respectively. ITOWVS and $\mathrm{CCH}$ has a weak correlation with CAF having values of -0.28 and -0.15 .

\subsection{Descriptive Statistics}

Table 4. Descriptive Statistics (Panel Data)

\begin{tabular}{llllll}
\hline & Mean & Median & Maximum & Minimum & Std. Dev. \\
\hline CAF & 0.33 & 0.32 & 0.64 & 0.13 & 0.12 \\
WGI & 0.11 & -0.19 & 1.98 & -1.93 & 1.05 \\
SS & 0.84 & 0.87 & 0.98 & 0.48 & 0.11 \\
FLC & 0.74 & 0.75 & 0.95 & 0.36 & 0.14 \\
GEN & 0.01 & -0.01 & 0.54 & -0.32 & 0.18 \\
\hline
\end{tabular}


Table 5. Descriptive Statistics (Cross Sectional Data)

\begin{tabular}{llllll}
\hline & Mean & Median & Maximum & Minimum & Std. Dev. \\
\hline CAF & 0.35 & 0.33 & 0.59 & 0.19 & 0.12 \\
PDI & 0.65 & 0.66 & 1.04 & 0.22 & 0.22 \\
IDV & 0.42 & 0.31 & 0.91 & 0.13 & 0.25 \\
MAS & 0.45 & 0.44 & 0.69 & 0.05 & 0.17 \\
ITOWVS & 0.38 & 0.33 & 0.86 & 0.04 & 0.21 \\
UAI & 0.69 & 0.75 & 1.00 & 0.29 & 0.22 \\
IVR & 0.50 & 0.50 & 0.97 & 0.00 & 0.26 \\
AICH & 0.07 & 0.06 & 0.19 & 0.00 & 0.05 \\
AICR & 0.19 & 0.15 & 0.54 & 0.00 & 0.14 \\
IILR & 0.50 & 0.44 & 0.77 & 0.27 & 0.17 \\
CCH & 0.58 & 0.58 & 0.69 & 0.47 & 0.06 \\
FOH & 0.46 & 0.44 & 0.78 & 0.35 & 0.08 \\
SS & 0.84 & 0.89 & 0.95 & 0.56 & 0.11 \\
FLC & 0.78 & 0.80 & 0.93 & 0.42 & 0.14 \\
GEN & 0.03 & 0.01 & 0.45 & -0.30 & 0.18 \\
\hline
\end{tabular}

\subsection{Regression Analysis}

Table 6. Regression

\section{Variable Coefficient t-Statistic Probability R-Square Adjusted}

R-Square

F-Statistic Durbin

\begin{tabular}{|c|c|c|c|c|c|c|c|c|}
\hline & & & & & & R-Sq & & Watson \\
\hline & $\mathrm{C}$ & 0.07 & 0.86 & 0.39 & & & & \\
\hline Model I & WGI & 0.10 & 2.74 & 0.01 & & & & \\
\hline (Panel with sub factors & SS & 0.18 & 2.16 & 0.03 & 0.91 & 0.88 & 0.00 & 2.38 \\
\hline Institutions combined) & FLC & 0.14 & 2.60 & 0.01 & & & & \\
\hline & GEN & 0.04 & 0.94 & 0.35 & & & & \\
\hline & $\mathrm{C}$ & 0.35 & 25.65 & 0.00 & & & & \\
\hline & WGI & -0.02 & -0.55 & 0.59 & & & & \\
\hline (Cross Sectional all & HI & 0.05 & 2.05 & 0.05 & 0.13 & 0.00 & 0.00 & 2.10 \\
\hline & WVS & -0.02 & -0.97 & 0.34 & & & & \\
\hline
\end{tabular}




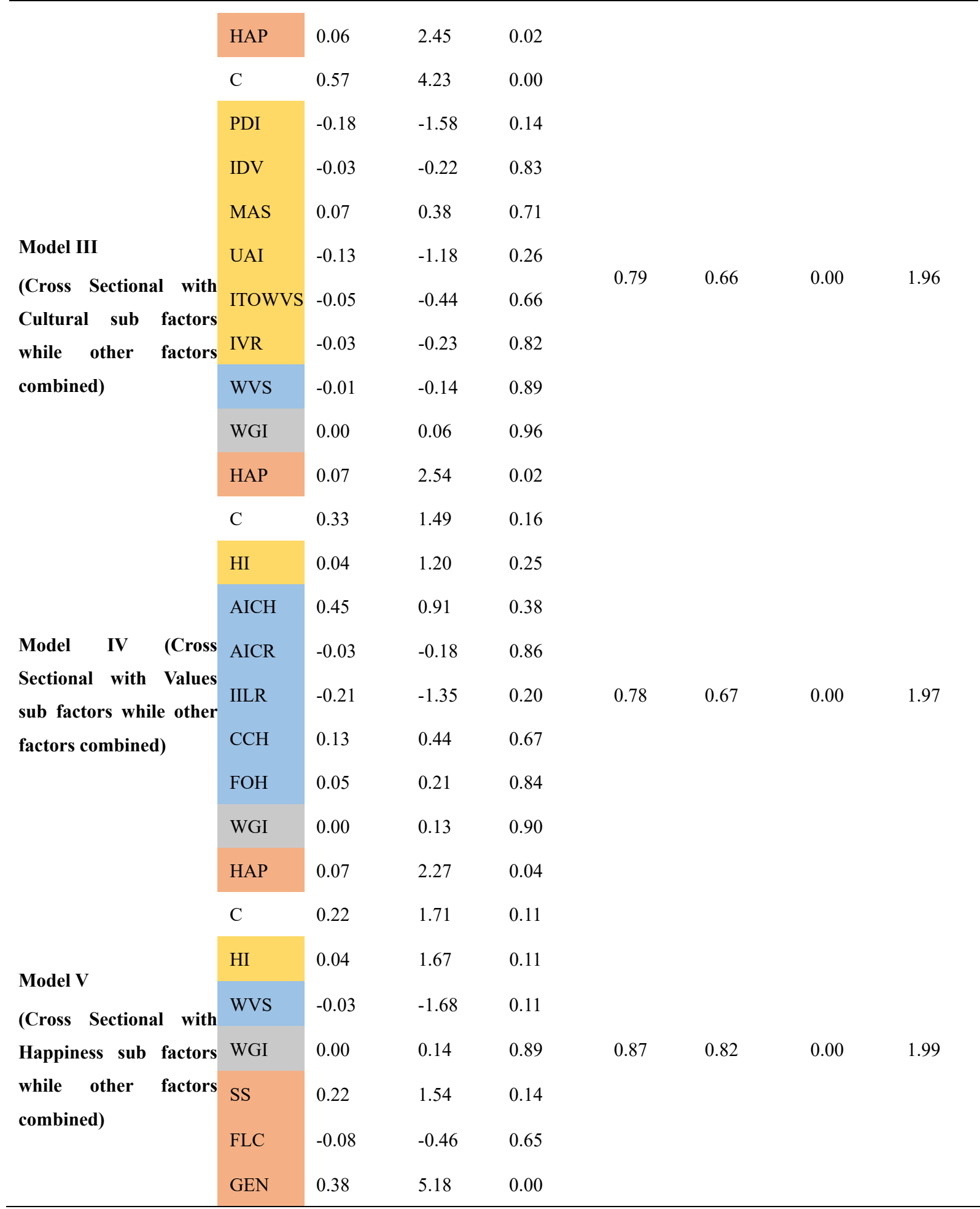

HAP $=$ Happiness $($ Combined $), \mathrm{SS}=$ Social Support, FLC $=$ Freedom to make Life Choices, GEN $=$ Generosity.

$\mathrm{HI}=$ Culture (Combined), PDI = Power Distance Index, IDV = Individualism-Collectivism, MAS = Masculinity-Femininity, UAI = Uncertainty Avoidance Index, ITOWVS = Long-Run Orientation-Short-Run Orientation, IVR = Indulgence- Restraint

WVS $=$ Values (Combined), AICH = Active or Inactive Membership of Charitable Humanitarian Organization, AICR = Active or Inactive Membership of Church or Religious 
Organization, IILR = Importance of Religion in Life, $\mathrm{CCH}=$ Confidence on Charitable Humanitarian Organization, $\mathrm{FOH}=$ Feeling of Happiness

WGI = Institutions (Combined), VA = Voice and Accountability, PS = Political Stability, GE $=$ Government Effectiveness, $\mathrm{RQ}=$ Regulatory Quality, $\mathrm{CC}=$ Control of Corruption, $\mathrm{RL}=$ Rule of Law.

In Table 6 Model I illustrate the relation among variables with the help of regression analysis. WGI, SS, and FLC has a significant relation with CAF since their significant level is less than 0.1 i.e. $0.01,0.03$ and 0.01 whereas GEN has an insignificant relation with CAF because its significant value is greater than 0.1 i.e. 0.35 respectively. The regression equation states that the constant value is positive which indicates that CAF will increase by 0.07 in a day. If WGI, SS, FLC and GEN increase by $1 \%$ than CAF will increase by $10 \%, 18 \%, 14 \%$ and $4 \%$ respectively.

Model II shows the relation among variables with the help of regression analysis. In this study WGI (World Governance Indicators), Hofstede Index (HI) (includes PDI, IDV, MAS, RQ, CC, and RL), World Value Survey (WVS) (includes AICH, AICR, IILR, CCH, and FOH) and Happiness Index (HAP) (includes SS, FLC, and GEN) are the independent variables.

$\mathrm{HI}$ and HAP has a significant relation with CAF since their significant level is less than 0.1 i.e. 0.05 and 0.02. Whereas WGI and WVS has an insignificant relation with CAF because their $\mathrm{p}$ values are 0.59 and 0.34 (which is greater than 0.1 ). The regression equation states that the constant value is positive which indicates that CAF will increase by 0.35 in a day. If $\mathrm{HI}$ and HAP increase by $1 \%$ than CAF will increase by $5 \%$ and $6 \%$ while if WGI and WVS decrease by $1 \%$ than CAF will also decrease by $2 \%$ and $2 \%$ respectively.

Model III demonstrates the linkage among variables by using regression. PDI, IDV, MAS, UAI, ITOWVS, IVR, WVS, WGI has an insignificant relation with CAF since their $\mathrm{p}$ value is $0.14,0.83,0.71,0.26,0.66,0.82,0.89$ and 0.96 (which is greater than 0.1 ) while HAP has a significant relation with CAF since its $\mathrm{p}$ value is 0.02 which is less than 0.1 . The regression equation states that the constant value is positive which indicates that CAF will increase by 0.57 in a day. If PDI, IDV, UAI, ITOWVS, IVR and WVS decrease by $1 \%$ than CAF will decrease by $18 \%, 3 \%, 13 \%, 5 \%, 3 \%$ and $1 \%$ while if MAS, WGI and HAP increase by $1 \%$ than CAF will also increase by $7 \%, 0.00 \%$ and $7 \%$ respectively.

Model IV also illustrates the association among variables with the help of regression. HI, $\mathrm{AICH}, \mathrm{AICR}, \mathrm{IILR}, \mathrm{CCH}, \mathrm{FOH}$, and WGI has an insignificant relation with CAF because their $p$ value is $0.25,0.38,0.86,0.20,0.67,0.84$ and 0.90 while HAP has a significant relation with $\mathrm{CAF}$ as its $\mathrm{p}$ value is 0.04 . The regression equation states that the constant value is positive which indicates that CAF will increase by 0.33 in a day. If $\mathrm{HI}, \mathrm{AICH}, \mathrm{CCH}, \mathrm{FOH}$, WGI and HAP increase by $1 \%$ than CAF will increase by $4 \%, 45 \%, 13 \%, 5 \%, 0.00 \%, 7 \%$ while if AICR and IILR decrease by $1 \%$ than CAF will also decrease by $3 \%$ and $21 \%$ respectively.

In Model V, WGI, HI, WVS, SS, and FLC has an insignificant relation with CAF because their $p$ value is $0.11,0.11,0.89,0.14$ and 0.65 while GEN has a significant relation with CAF 
as its $p$ value is 0.00 . The regression equation states that the constant value is positive which indicates that CAF will increase by 0.22 in a day. If HI, WGI, SS, and GEN increase by $1 \%$ than CAF will increase by $4 \%, 0.00 \%, 22 \%$ and $38 \%$ while if WVS and FLC decrease by $1 \%$ than $\mathrm{CAF}$ will also decrease by $3 \%$ and $8 \%$ respectively.

The average value of R-Square for all the 5 models is about $82 \%$ which means that CAF will change by $90.709 \%$ due to the changes in independent variables. However, the average value of the Adjusted R-Square is about 74\%. This clearly indicates that some leftover variables are not included in the equation. Durbin Watson states that there is no autocorrelation because the average value is around 2. F-Statistic shows how much of your model is the overall fit and the average value of F-statistic is 0.000000 .

\section{Discussions}

Our overall findings revealed that in Model I WGI, SS and FLC has a significant relation with CAF whereas GEN has an insignificant relation with CAF. In Model II HI and HAP has a significant relation with CAF. Whereas WGI and WVS has an insignificant relation with CAF. In Model III PDI, IDV, MAS, UAI, ITOWVS, IVR, WVS, WGI has an insignificant relation with $\mathrm{CAF}$, while HAP has a significant relation with CAF. In Model IV HI, AICH, AICR, IILR, CCH, FOH and WGI has an insignificant relation with CAF while HAP has a significant relation with CAF. In Model V, WGI, HI, WVS, SS, and FLC has an insignificant relation with CAF while GEN has a significant relation with CAF.

The reasons for insignificant results can be diverse values, governance, culture, etc. because all of these variables vary from nation to nation. In the last ten years so many bad things had happened like bad law and order situation, economic instability, political instability, inflation, increase in GDP per capita, changes in monetary policies, energy crisis and these are the reasons for insignificancy. Another reason is that some countries government has taken a lot of loan from International Monetary Fund (IMF) and those countries government are unable to pay off these loans due to this government has increased taxes on industrial sector as well as on other sectors that is why a lot of people have to pay heavy amount of taxes. Various firms financed most of their assets through debt which indicates that they have to pay a heavy amount of interest due to which companies' sales will not grow and thus they will not generate profit. Weak marketing plan, lack of trust and technological advancement can also be one of the reasons for the insignificant result.

\section{Conclusion}

A lot of countries engage themselves in the activities of philanthropy and good governance is very essential for the success of any nation. This paper examines the effect of value, culture, happiness, and institution on philanthropy. Culture is measured by Hofstede index (i.e. individualism-collectivism, masculinity-femininity, long and short-run orientation, uncertainty avoidance, power distance, and indulgence-restraint). The measurement of value is WVS (World Value Survey) and it consists of the emotion of happiness, active/ inactive membership of a church or religious organization, important in life; religion, confidence on charitable/ humanitarian organization and active/ inactive membership of charitable/ 
humanitarian organization. Institutions are measured by WGI (World Governance Indicators) and it consists of corruption, regulatory quality, accountability and voice, rule of law, political stability and government effectiveness), the sub-variables of happiness (index) are social support, freedom to take decisions and generosity and world's philanthropy is measured by CAF (Charitable Aid Foundation) world giving index. We have gathered panel data (from the period 2010 to 2014) of CAF index, happiness index and WGI of 62 countries and cross-sectional data of CAF index, Hofstede index, WGI, happiness index and WVS of 24 countries. Regression, descriptive statistics and correlation were the statistical tools that we have applied in our study. The outcomes of Model I (of panel data) of the study shows that philanthropy is significantly affected by institutions, social support and freedom to take decisions, which means we accept the alternate hypothesis and reject the null hypothesis although there is no relation between generosity and philanthropy. Hence we accept the null hypothesis and reject the alternate hypothesis.

The findings of cross-sectional data indicate that in Model II HI and HAP has a significant relation with CAF (thus in this situation we accept the alternate hypothesis and reject the null hypothesis) while WGI and WVS has an insignificant relation with CAF, therefore here we accept the null hypothesis and reject the alternate hypothesis. In Model III PDI, IDV, MAS, UAI, ITOWVS, IVR, WVS, WGI has an insignificant relation with CAF (therefore we accept the null hypothesis and reject the alternate hypothesis) while HAP has a significant relation with CAF (thus we accept the alternate hypothesis and reject the null hypothesis). In Model IV HI, AICH, AICR, IILR, CCH, FOH and WGI has an insignificant relation with CAF (therefore we accept the null hypothesis and reject the alternate hypothesis) while HAP has a significant relation with CAF (as a result we accept the alternate hypothesis and reject the null hypothesis). In Model V, WGI, HI, WVS, SS, and FLC has an insignificant relation with CAF (therefore we accept the null hypothesis and reject the alternate hypothesis) while GEN has a significant relation with $\mathrm{CAF}$, (hence in this situation we accept the alternate hypothesis and reject the null hypothesis).

The study suggests that charitable organizations should personify their value in order to build trust among the public. Countries should improve their governance because this will lead to equality and by doing this countries will also manage resources efficiently and effectively. In future researchers can conduct the research on the same topic by using other countries or regions. We have applied regression, correlation and descriptive statistics so other studies can apply GMM (Generalized Method of Moments), Hausman test, etc. Further studies can also consider other variables such as capital structure, profitability, etc with culture, value, institutions, happiness, and philanthropy to find out more efficient end results.

It can be recommended that countries should improve their governance because this will lead to equality and by doing this countries will also manage resources efficiently and effectively. Charitable organizations should personify their value in order to build trust among the public. A lot of improvement in the marketing plan and technological advancement is required.

\subsection{Limitations of the Study}

For this study, 62 countries panel data was collected while 24 countries cross-sectional data 
was acquired because for the rest of the countries data of some variables was not available. Panel data was gathered from the period 2010 to 2014 as data of current and prior years was unavailable for some countries.

\section{References}

Accountability and Voice, reflects citizen's participation regarding the selection of their government and freedom of media, expression, and association, (1996 to 2017). range from -2.5 to 2.5 , Retrieved from https://info.worldbank.org/governance/wgi/

Active/ inactive membership of a church or religious organization, how much actively or inactively an individual takes part in religious or church-related activities, Retrieved from http://www.worldvaluessurvey.org/wvs.jsp

Active/ inactive membership of charitable/ humanitarian organization, how much actively or inactively an individual takes part in charitable activities, Retrieved from http://www.worldvaluessurvey.org/wvs.jsp

Ahmad, Z., \& Saleem, A. (2014). Impact of Governance on Human Development. Pakistan Journal of Commerce and Social Sciences (PJCSS), 8(3), 612-628.

Alemán, J., \& Woods, D. (2016). Value Orientations From The World Values Survey: How Comparable are They Cross-Nationally? Comparative Political Studies, 49(8), 1039-1067. https://doi.org/10.1177/0010414015600458

Andrijauskienè, M., \& Dumčiuvienė, D. (2017, October). Hofstede's Cultural Dimensions and National Innovation Level. In DIEM: Dubrovnik International Economic Meeting (Vol. 3, No. 1, pp. 189-205). Sveučilište u Dubrovniku.

Ansah, M. O. (2015). Cultural Dimension in Marketing Managers'Decision Making: An Application of Geert Hofstede Index for Ghana. European Journal of Research and Reflection in Management Sciences, 3(2).

Apaza, C. R. (2009). Measuring governance and corruption through the worldwide governance indicators: Critiques, responses, and ongoing scholarly discussion. PS: Political Science \& Politics, 42(1), 139-143. https://doi.org/10.1017/S1049096509090106

Asuquo, E. E. (2015). The Role of Institutions and Governance on Economic Performance in Selected sub-Saharan African Countries.

Awan, R. U., Akhtar, T., Rahim, S., Sher, F., \& Cheema, A. R. (2018). Governance, Corruption and Economic Growth: A Panel Data Analysis of Selected SAARC Countries. Pakistan Economic and Social Review, 56(1), 1-20.

Bayar, Y. (2016). Public Governance and Economic Growth in The Transitional Economies of The European Union Transylvanian Review of Administrative Sciences, 12(48), 5-18.

Borgonovi, F. (2008). Doing well by doing good. The relationship between formal volunteering and self-reported health and happiness. Social science \& medicine, 66(11), 2321-2334. https://doi.org/10.1016/j.socscimed.2008.01.011 
CAF World Giving Index. (2011). Retrieved from https://www.cafonline.org/docs/ default-source/about-us-publications/world_giving_index_2011_191211.pdf

CAF World Giving Index. (2012), Retrieved from https://www.cafonline.org/docs /default-source/about-us-publications/worldgivingindex2012web.pdf?sfvrsn=e315f440_4

CAF World Giving Index. (2013), Retrieved from https://www.cafonline.org/docs/ default-source/about-us-publications/worldgivingindex2013_1374aweb.pdf?sfvrsn=e215f440 4

CAF World Giving Index. (2014), Retrieved from https://www.cafonline.org/docs/ default-source/about-us-publications/caf_wgi2014_report_1555awebfinal.pdf

CAF World Giving Index, shows volunteering, helping and giving behavior globally, (2010), Retrieved from https://www.cafonline.org/docs/default-source/about-us-publications/ worldgivingindex28092010print.pdf

Çarkoğlu, A., Aytaç, S. E., \& Campbell, D. A. (2017). Determinants of Formal Giving in Turkey. Journal of Muslim Philanthropy \& Civil Society, 1(1).

Confidence on charitable/ humanitarian organization, it shows how much people trust a charitable organization, Retrieved from http://www.worldvaluessurvey.org/wvs.jsp

Corruption, measures the use of public power for personal interest, (1996 to 2017), range from -2.5 to 2.5, Retrieved from https://info.worldbank.org/governance/wgi/

Dimitrova, B. V., Rosenbloom, B., \&amp; Andras, T. L. (2016). The Impact of National Cultural Values on Retail Structure: Evidence from the World Values Survey. International Marketing Review, 33(6), 894-920. https://doi.org/10.1108/IMR-11-2014-0361

Dulababu, T. (2017). Global Happiness: Continental and Cross-Cultural Models Perspective. J Glob Econ, 5(268), 2. https://doi.org/10.4172/2375-4389.1000268

Einolf, C. J. (2017). Cross-national differences in charitable giving in the west and the world. Voluntas: International Journal of Voluntary and Nonprofit Organizations, 28(2), 472-491. https://doi.org/10.1007/s11266-016-9758-4

Emotion of happiness, feeling good or happy. Retrieved from http://www.worldvaluessurvey.org/wvs.jsp

Freedom of choice, the freedom that is giving to people regarding their life decisions, (2005 to 2017). Retrieved from https://www.Online-data-for-chapter-2-whr-2016.xlsx

Garcia, S., Osili, U., \& Kou, X. (2017, July). Measuring Philanthropic Freedom Across Countries. In 8th ERNOP Conference, Copenhagen (pp. 13-14).

Generosity, being generous and kind to someone and willingly donating money to help others, (2005 to 2017). Retrieved from https://www.Online-data-for-chapter-2-whr-2016.xlsx

Gorodnichenko, Y., \& Roland, G. (2017). Culture, Institutions, and The Wealth of Nations. Review of Economics and Statistics, 99(3), 402-416. https://doi.org/10.2139/ssrn.1682575 
Government Effectiveness, reflects policy implementation and formulation by the government and also shows the quality of public and civil services, (1996 to 2017), range from -2.5 to 2.5 , Retrieved from https://info.worldbank.org/governance/wgi/

Guo, Q., Li, X., \& Qiao, X. (2018). Indulgence and long term orientation influence prosocial behavior at national level. Frontiers in psychology, 9, 1798. https://doi.org/10.3389/fpsyg.2018.01798

Hassan, S. H., Masron, T. A., Mohamed, N., \& Thurasamy, R. (2018). Antecedents Of Trust Towards The Attitude of Charitable Organisation in Monetary Philanthropic Donation Among Generation-Y Asian Academy of Management Journal, 23(1). https://doi.org/10.21315/aamj2018.23.1.3

Helliwell, J. F., Huang, H., Grover, S., \& Wang, S. (2018). Empirical Linkages Between Good Governance and National Well-Being. Journal of Comparative Economics, 46(4), 1332-1346. https://doi.org/10.3386/w20686

Howard, M. C. (2016). A review of exploratory factor analysis decisions and overview of current practices: What we are doing and how can we improve? International Journal of Human-Computer Interaction, 32(1), 51-62. https://doi.org/10.1080/10447318.2015.1087664 Important in life; religion, it shows how much religion is important in your life. Retrieved from http://www.worldvaluessurvey.org/wvs.jsp

Individualism-Collectivism, interdependence maintained by the society among its citizens or members, Retrieved from https:/geerthofstede.com/research-and-vsm/dimension-data -matrix/

Indulgence-Restraint, society's control over their desires and wants. Retrieved from https:/geerthofstede.com/research-and-vsm/dimension-data-matrix/

Irfan, M. I. (2016). Cultural Dimensions of Hofstede and Their Impact on Organizational Performance in Sri Lanka. Imperial Journal of Interdisciplinary Research, 2(10), 1160-1169.

Kilishi, A. A., Mobolaji, H. I., Yaru, M. A., \& Yakubu, A. T. (2013). Institutions and economic performance in Sub-Saharan Africa: A dynamic panel data analysis. Journal of African Development, 15(2), 91-119.

Lee, M. A., \& Kawachi, I. (2019). The keys to happiness: Associations between personal values regarding core life domains and happiness in South Korea. PloS one, 14(1), e0209821. https://doi.org/10.1371/journal.pone.0209821

Leite, D. N., Silva, S. T., \& Afonso, O. (2014). Institutions, economics and the development quest. Journal of Economic Surveys, 28(3), 491-515. https://doi.org/10.1111/joes. 12038

Long-run Orientation-Short-run orientation, society's focus on past, future and present, Retrieved from https:/geerthofstede.com/research-and-vsm/dimension-data-matrix/ 
Luria, G., Cnaan, R. A., \& Boehm, A. (2015). National Culture and Prosocial Behaviors: Results from 66 countries. Nonprofit and Voluntary Sector Quarterly, 44(5), 1041-1065. https://doi.org/10.1177/0899764014554456

Masculinity-Femininity, society'smembers favor heroism, achievement or modesty.

Matei, M. C., \& Abrudan, M. M. (2018). Are National Cultures Changing? Evidence from the World Values Survey. Procedia-Social and Behavioral Sciences, 238, 657-664. https://doi.org/10.1016/j.sbspro.2018.04.047

Morris, M. W. (2014). Values as the essence of culture: Foundation or fallacy? Journal of Cross-Cultural Psychology, 45(1), 14-24. https://doi.org/10.1177/0022022113513400

Musikanski, L., Cloutier, S., Bejarano, E., Briggs, D., Colbert, J., Strasser, G., \& Russell, S. (2017). Happiness index methodology. Journal of Social Change, 9(1), 2. https://doi.org/10.5590/JOSC.2017.09.1.02

Phillips, S., \& Jung, T. (2016). A New 'New' Philanthropy: from impetus to impact. The Routledge companion to philanthropy.

Pholphirul, P. (2015). Happiness from Giving: Quantitative Investigation of Thai Buddhists. Applied Research in Quality of Life, 10(4), 703-720. https://doi.org/10.1007/s11482014-9349-8

Political Stability, measures political instability or stability of the country, (1996 to 2017), range from -2.5 to 2.5, Retrieved from https://info.worldbank.org/governance/wgi/

Power Distance, members of the culture believe that there is an unequal distribution of power, Retrieved from https://geerthofstede.com/research-and-vsm/dimension-data-matrix/; https://www.hofstede-insights.com/

Regulatory Quality, reflects implementation and formulation of sound regulations and policies for private sector, (1996 to 2017), range from -2.5 to 2.5 , Retrieved from https://info.worldbank.org/governance/wgi/

Rinuastuti, H., Hadiwidjojo, D., Rohman, F., \& Khusniyah, N. (2014). Measuring Hofstede's Five Cultural Dimensions at Individual Level and its Application to Researchers in Tourists' Behaviors. International Business Research, 7(12), 143. https://doi.org/10.5539/ibr. v7n12p143

Rule of Law, reflects that how much agents stand by the society's rules, (1996 to 2017), range from -2.5 to 2.5, Retrieved from https://info.worldbank.org/governance/wgi/

Smith, P. B. (2015). To Lend Helping Hands: In-Group Favoritism, Uncertainty Avoidance, and The National Frequency of Pro-Social Behaviors. Journal of Cross-Cultural Psychology, 46(6), 759-771.https://doi.org/10.1177/0022022115585141

Social Support, helping someone in their difficult or problematic times and contributing towards the well being of the nation, (2005 to 2017). Retrieved from https://www.Online-data-for-chapter-2-whr-2016.xlsx 
Stojcic, I., Kewen, L., \& Xiaopeng, R. (2016). Does Uncertainty Avoidance Keep Charity Away? Comparative Research Between Charitable Behavior and 79 National Cultures. Culture and Brain, 4(1), 1-20. https://doi.org/10.1007/s40167-016-0033-8

Tabellini, G. (2010). Culture and institutions: economic development in the regions of Europe. Journal of the European Economic association, 8(4), 677-716. https://doi.org/ 10.1111/j.1542-4774.2010.tb00537.x

Uncertainty Avoidance, society's forbearance for unclarity, Retrieved from https:/geerthofstede.com/research-and-vsm/dimension-data-matrix/

Whalen, J. M. (2016). Hofstede Model and National Cultures of Learning: A Comparison of Undergraduate Survey Data, The (Doctoral dissertation, Colorado State University. Libraries).

Wiepking, P. (2010). Democrats support international relief and the upper class donates to art? How opportunity, incentives and confidence affect donations to different types of charitable organizations. Social Science Research, 39(6), 1073-1087. https://doi.org/10.1016/ j.ssresearch.2010.06.005

Wilson, J. (2000). Volunteering. Annual review of sociology, 26(1), 215-240. https://doi.org/10.1146/annurev.soc.26.1.215

Ye, D., Ng, Y. K., \& Lian, Y. (2015). Culture and Happiness. Social indicators research, 123(2), 519-547. https://doi.org/10.1007/s11205-014-0747-y

\section{Copyright Disclaimer}

Copyright reserved by the author(s).

This article is an open-access article distributed under the terms and conditions of the Creative Commons Attribution license (http://creativecommons.org/licenses/by/3.0/). 